Portland State University

PDXScholar

\title{
An Examination of the Relationship between Work Involvement and Family Involvement and Work- family Conflict in Dual-career Families
}

\author{
Elizabeth Jean Allen \\ Portland State University
}

Follow this and additional works at: https://pdxscholar.library.pdx.edu/open_access_etds

Part of the Psychology Commons

Let us know how access to this document benefits you.

\section{Recommended Citation}

Allen, Elizabeth Jean, "An Examination of the Relationship between Work Involvement and Family Involvement and Work-family Conflict in Dual-career Families" (1993). Dissertations and Theses. Paper 4988.

https://doi.org/10.15760/etd.6864

This Thesis is brought to you for free and open access. It has been accepted for inclusion in Dissertations and Theses by an authorized administrator of PDXScholar. Please contact us if we can make this document more accessible: pdxscholar@pdx.edu. 


\section{THESIS APPROVAL}

The abstract and thesis of Elizabeth Jean Allen for the Master of Science in

Psychology were presented July 23,1993 , and accepted by the thesis committee and the department.

COMMITTEE APPROVALS:

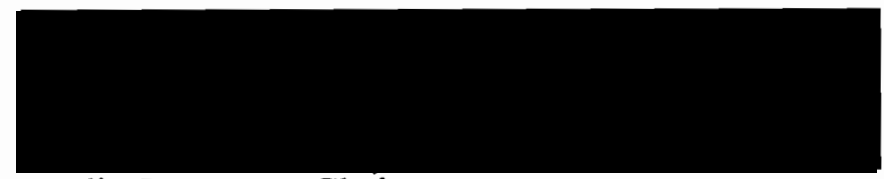

Leslie Hammer, Chair

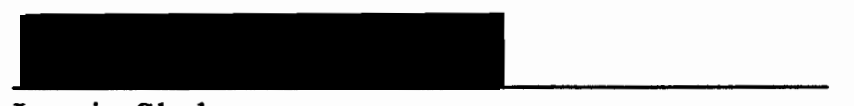

Laurie Skokan
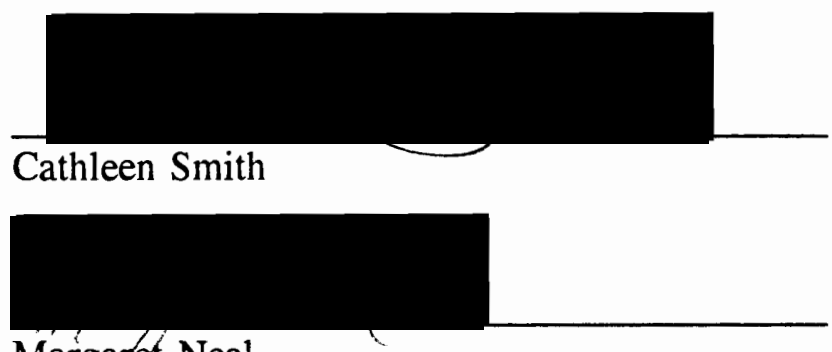

Margaret Neal

Representative of the Office of Graduate Studies

DEPARTMENT APPROVAL:

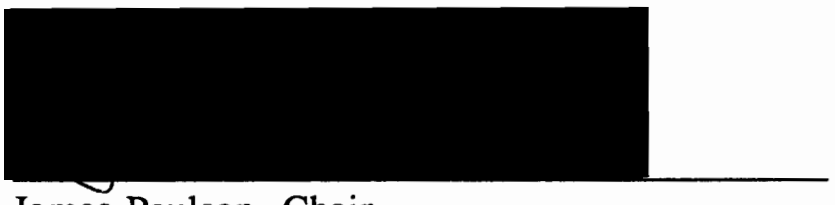

James Paulson, Chair

Department of Psychology

ACCEPTED FOR PORTLAND STATE UNIVERSITY BY THE LIBRARY

by on 27 Powemer 1995 


\begin{abstract}
An abstract of the thesis of Elizabeth Jean Allen for the Master of Science in Psychology presented July 23, 1993.
\end{abstract}

Title: An Examination of the Relationship Between Work Involvement and Family

Involvement and Work-Family Conflict in Dual-Career Families.

The present study examined the relationship between work involvement and family involvement and work-family conflict in dual-career families. Four hundred thirty-six couples (436 females; 436 males; $N=872$ ) in dual-career relationships were recruited from a bank organization in the Northwest United States. The survey questionnaire contained three sections to measure work and family involvement, work-family conflict, and sociodemographic information. Data analyses were conducted using multiple regression analysis and a $1 \mathrm{X} 4$ ANOVA to examine the proposed relationships among the study variables. Results demonstrated the following: across study participants, work involvement accounted for a significant amount of variance in work-family conflict; family involvement accounted for a significant amount of variance in work-family conflict; the number of dependents accounted for a significant amount of variance in work-family conflict; work-family conflict was significantly higher for females than for males; 
and couples who were symmetric in both work involvement and family involvement experienced lower levels of work-family conflict than couples who were asymmetric in both work involvement and family involvement. The test of the effects of one's spouse/partner's work involvement and one's spouse/partner's family involvement on the individual's work-family conflict was not significant. An examination of the moderating effects of the number of dependents and age of youngest (or only) child on the relationships between work involvement and family involvement and work-family conflict was not significant. Implications of the study and future research ideas are discussed. 
AN EXAMINATION OF THE RELATIONSHIP BETWEEN

WORK INVOLVEMENT AND FAMILY INVOLVEMENT

AND WORK-FAMILY CONFLICT IN DUAL-CAREER FAMILIES

by

ELIZABETH JEAN ALLEN

A thesis submitted in partial fulfillment of the requirements for the degree of

\author{
MASTER OF SCIENCE \\ in \\ PSYCHOLOGY
}

Portland State University

1995 


\section{TABLE OF CONTENTS}

LIST OF TABLES .

PAGE

INTRODUCTION $\ldots \ldots \ldots \ldots \ldots \ldots \ldots \ldots \ldots$

REVIEW OF THE LITERATURE $\ldots \ldots \ldots \ldots \ldots \ldots$

Dual-Career Families $\ldots \ldots \ldots \ldots \ldots \ldots \ldots \ldots \ldots$

Work-Family Conflict . . . . . . . . . . . . . . 10

Work Involvement and Family Involvement $\ldots \ldots \ldots \ldots \ldots$

Relationship Between Work Involvement and Family Involvement

and Work-Family Conflict . . . . . . . . . . . 21

DESCRIPTION OF THE PROBLEM . . . . . . . . . . . 27

Rationale for Study . . . . . . . . . . . . . . . 27

Hypotheses . . . . . . . . . . . . . . . 30

METHOD . . . . . . . . . . . . . . . . . . . 39

Respondents . . . . . . . . . . . . . . . . . . . 39

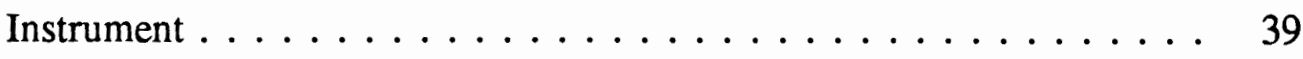

Sociodemographic Data . . . . . . . . . . . . . . . . . . . 39

Work Involvement and Family Involvement . . . . . . . . 40

Work-Family Conflict . . . . . . . . . . . . . . . . 41

Procedure $\ldots \ldots \ldots \ldots \ldots \ldots \ldots \ldots \ldots \ldots \ldots \ldots$ 


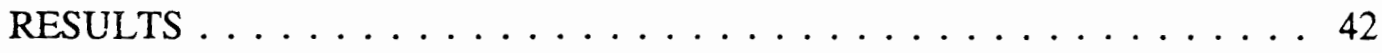

Descriptive Statistics . . . . . . . . . . . . . . 42

Family Characteristics . . . . . . . . . . 42

Work Characteristics . . . . . . . . . . . . . 42

Work-Family Measures . . . . . . . . . . . . . . . 43

Correlation Matrix for Study Variables . . . . . . . . . . . 44

Tests of Hypotheses . . . . . . . . . . . . . . 45

Overall Work-Family Conflict . . . . . . . . . . . . 45

Employee Work-Family Conflict . . . . . . . . . . . . 47

Spouse Work-Family Conflict . . . . . . . . . . . . 48

Sociodemographic Variables . . . . . . . . . . . . . 50

Gender Differences in Work-Family Conflict . . . . . . . 51

Patterns of Work Involvement and Family Involvement

by Couples . . . . . . . . . . . . . . 51

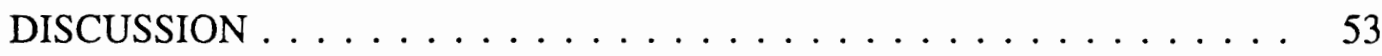

Tests of Hypotheses . . . . . . . . . . . . . . . 53

Limitations of the Study . . . . . . . . . . . . . 65

Lack of Objective Measures of Work Involvement and Family

Involvement and Problems Associated with

Using Self-Reports . . . . . . . . . . . . . 65

Limited Generalizations to Dual-Career Families . . . . . . 67

The Comparison of Employees to Spouses Instead of

Husbands to Wives . . . . . . . . . . . 68

The Need for Path Analysis . . . . . . . . . . . . . . 69

Implications for Future Research . . . . . . . . . . . . . . 69

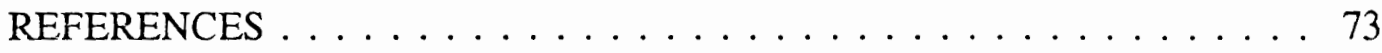

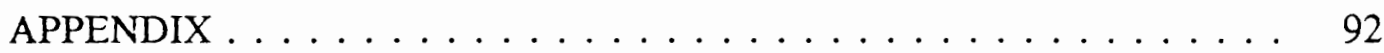




\section{LIST OF TABLES}

TABLE

Number of Survey Respondents, Means and Standard Deviations

for Family Characteristics Computed by Couples . . . 79

II Distribution of Family Characteristics for Survey

Respondents ................. 81

III Means and Standard Deviations for Work Characteristics

by Couples . . . . . . . . . . . . . . . 84

IV Distribution of Work Characteristics for Survey Respondents . . 85

V Means and Standard Deviations for Work-Family Scales

by Couples . . . . . . . . . . . . 87

VI Pearson Correlation Coefficients for Study Variables . . . . 88

VII Results of Multiple Regression Analysis of Work-Family

Conflict on Study Variables . . . . . . . . . . . . . 89

VIII Results of Multiple Regression Analysis of Employee

Work-Family Conflict on Spouse Study Variables . . 90

IX Results of Multiple Regression Analysis of Spouse/Partner

Work-Family Conflict on Employee Study Variables . . 91 
The nature of the work force is changing and will continue to change in terms of gender, race, and age, as we approach the year 2000 (Goff, Mount, \& Jamison, 1990; Offerman \& Gowing, 1990; Zedeck \& Mosier, 1990). Women currently comprise $44.5 \%$ of the work force, and by the year 2000 women will comprise over $47 \%$ (Leap \& Crino, 1989). According to Leap and Crino, since the mid-1970s women have accounted for approximately two out of every three entrants into the work force. Particularly, the number of women with young children who participate in the work force has been increasing dramatically (Goff et al.). More than half of all children under age six had mothers in the work force in 1987 (U.S. Department of Labor, 1987).

As more women enter the work force and dual-career families proliferate, it becomes increasingly necessary to examine the relationship between work involvement and family involvement and work-family conflict. Involvement includes individuals' subjective reactions (e.g., psychological attachment) to their work and family roles, although involvement has also been shown to include objective factors (e.g., the number of hours spent in work and family activities) (Duxbury \& Higgins, 1991). Lodahl and Kejner's (1965) model of work involvement incorporates individuals' psychological response to their work, the degree to which individuals identify with their work, and the relative importance of work to individuals' self-image and self-concept. Similarly, the Yogev and Brett (1985) model of family involvement incorporates the degree to which individuals identify with their family, the relative 
importance of the family to individuals' self-image and self-concept, and individuals' commitment to their family.

Work-family conflict is defined by Greenhaus and Beutell (1985) as: "a form of interrole conflict in which role pressures from the work and family domains are mutually incompatible in some respect" (p. 77). In Kahn, Wolfe, Quinn, Snoek, and Rosenthal's (1964) description of role conflict, interrole conflict was defined as "the simultaneous occurrence of work and family pressures in which compliance with one role makes it more difficult to comply with the other role". Thus, work-family conflict is the interrole conflict arising from opposing pressures generated through participation in both work and family roles (Greenhaus \& Beutell).

Dual-career families are particularly appropriate for studying the relationship between work involvement and family involvement and work-family conflict, because these couples are naturally occurring dyads rather than couples who have been matched on some variable (e.g., levels of work involvement and family involvement). A key source of stress for individuals managing multiple role pressures is the nature of their work involvement and family involvement (Amatea, Cross, Clark, \& Bobby, 1986). High work involvement and high family involvement have been shown to be positively related to the number of hours spent in work and family activities, respectively (Greenhaus \& Beutell, 1985; Pleck, 1977). Similarly, an aspect of work-family conflict defined by Greenhaus and Beutell (i.e., time-based conflict) is a direct function of the number of hours individuals spend in work and family roles. 
Participation in the work (family) role is made more difficult by virtue of participation in the family (work) role (Greenhaus \& Beutell, 1985). Perhaps the degree of involvement in work and family domains is similar (symmetric) across both partners/spouses for some couples and drastically different (asymmetric) across both partners/spouses for others. That is, the couple as a unit may be similarly involved in work and/or family roles or each partner's levels of involvement in work and family roles, respectively, may be the opposite of one's partner's levels of involvement (Yogev \& Brett, 1985). Also, the couple's perceived level of work-family conflict may be similar or dissimilar. Through the examination of pressures arising from incompatible work involvement and family involvement patterns, it is possible to better understand the nature of the relationship between work involvement and family involvement and work-family conflict.

The emergence of dual-career families is a significant social and economic change that requires organizations to become more adaptive to the needs of their employees in order to facilitate a balance between employees' work involvement and family involvement. The purpose of the present study was to examine the nature of the relationship between work involvement and family involvement and work-family conflict in dual-career families through the couple as the unit of analysis. 
Review of the Literature

\section{Dual-Career Families}

The dual-career family has been defined as a unit where adult members of the household pursue careers (i.e., are employed) and at the same time maintain a family life that may include children (Rapoport \& Rapoport, 1971). It is widely acknowledged that dual-career families are on the rise in this country (DiBenedetto \& Tittle, 1990; Greenhaus, Parasuraman, Skromme Granrose, Rabinowitz, \& Beutell, 1989; Gupta \& Jenkins, 1985; Leap \& Crino, 1989). The number of dual-career couples in the United States increased $267 \%$ to 3.3 million between 1960 and 1983 (Sekaran, 1986). Furthermore, it is anticipated that the prevalence of dual-career relationships will continue to grow rapidly in the near future (Sekaran). The dual-career family is considered to be a modal pattern that is of particular interest due to the couples' simultaneous participation in both work and family roles (Rapoport \& Rapoport, 1976).

A constellation of dual-career family types exists rather than dual-career families being represented by a single uniform or homogeneous family pattern (Rapoport \& Rapoport, 1976). Rapoport and Rapoport state that dual-career families are a category of family structure in which there are variations in clusters of variables with distinguishable contrasts. Dual-career couples vary according to whether or not they have children, the number of children they have, and how they allocate their level of 
involvement to the work and family domains (Rapoport \& Rapoport). Influenced by the hard economic times, dual-career couples without children are on the rise (Rice, 1979). Some couples may decide to forego children in order to pursue their careers and maintain a close relationship with their spouses/partners. Also, a significant and increasing number of couples are choosing to live together in an extended relationship without the formal legal bonding of marriage (Rice). In the present study, dual-career families are defined as a relationship between married and unmarried couples (both with and without children) in which each spouse/partner is a member of the work force and the couple has lived together for a minimum of three years.

The requirement of living together in an extended relationship arises from the fact that couples who are in a dual-career relationship are expected to have a minimum level of commitment to the relationship (Gupta \& Jenkins, 1985). It is therefore expected that the requirement of sharing a common residence for a minimum of three years would meet a minimum level of commitment to the relationship. Gupta and Jenkins view a dual-career "couple" as two partners, each of whom feels an emotional commitment to the other partner and to his/her work. The term "career" has often been associated with a high degree of work commitment and progression within a single organization or across a variety of organizations (Gupta \& Jenkins, 1985; Rapoport \& Rapoport, 1971). However, more recently the term "career" has been used more broadly as a pattern of work-related experiences that spans the course of an individual's life. Also, the terms "career" and "job" may be operationally distinct or used interchangeably. Gupta and Jenkins have suggested that 
it is useful to view work roles as falling on a continuum that ranges from no commitment/progression at one end to high commitment/progression at the other end. Therefore, for the purpose of this study the term "career" is conceptualized to broadly include varying degrees of commitment/progression in order to be consistent with this emerging and expanded concept of a career. The personal and organizational experiences of dual-career families are likely to be markedly different from the experiences of other families (Gupta \& Jenkins).

It is anticipated that over half of all families will be dual-career families by the year 2000 with a corresponding increase in the number of women combining traditional family responsibilities and employment duties (DiBenedetto \& Tittle, 1990). Women are either pursuing careers throughout the marital life cycle or are returning to the work force after an absence for parental or educational purposes (Rice, 1979). Although it has been suggested that men are increasingly sharing the responsibility for the family (Amatea et al., 1986), and their priorities are shifting away from work to the family (Duxbury \& Higgins, 1991), empirical studies have failed to support increased levels of family involvement among men. The demands from two careers add stress to the couple's relationship and lead to higher levels of work-family conflict. When both partners have careers, the process of role and task division requires flexibility and cooperation (Rice). Patterns of work involvement and family involvement emerge in both single- (one spouse works) and dual-career couples (Yogev \& Brett, 1985). 
Yogev and Brett (1985) described the general typology of single- and dual-career couples by looking at the patterns of each spouse's involvement in work and family activities (defined as cross-spouse patterns of involvement). Two-hundred forty-five married couples (average age was 35 years old) with children living at home participated in the study (Yogev \& Brett). Couples with only the husband employed $(N=103)$ were used for the single-career couples. The authors examined the relative frequency of four patterns of couples' involvement: 1) symmetric in both work and family roles (both spouses are each similarly involved in both work and family roles); 2) asymmetric in both work and family roles (each spouse's involvement in work and family is opposite from the other spouse's involvement); 3) symmetric family-asymmetric work (couples who are similarly involved in family, but their degree of work involvement is dissimilar); 4) symmetric work-asymmetric family (couples who are similarly involved with work, but their degree of family involvement is dissimilar). The most frequent family pattern found was symmetric in all roles and the second most frequent was symmetric family-asymmetric work. The correlation between the husbands' and the wives' work involvement was not significant. The correlation between the husbands' and the wives' family involvement was significant for both dual- $(\underline{r}=.33, \underline{p}<.01)$ and single-career $(\underline{r}=.36, \underline{p}<.01)$ couples (Yogev \& Brett).

The research by Yogev and Brett (1985) revealed important findings: couples who were symmetric in both their work involvement and family involvement were more prevalent among both dual- and single-career couples than were couples who 
were asymmetric in work involvement and family involvement, and the cross-spouse interactions of work involvement and family involvement were supported among dual-career couples but were not supported among single-career couples. That is, the interactions between couples' work involvement and family involvement were significant only among the dual-career couples. Yogev and Brett explained that in dual-career couples, pressure from both partners working may force the husband and wife to both participate in managing the demands of work that affect the family and the demands of family that affect work. Gradually couples develop a coordinated pattern of routines and responsibilities to adequately manage their demands.

Dual-career couples' involvement in work and family roles is an indication of that pattern (Yogev \& Brett).

According to Rice (1979), dual-career families represent a high-stress lifestyle due to the combination of work and family role activities for the couple. These couples can experience stress in the execution of each work role, each family role, and the joint execution of work and family roles (Gupta \& Jenkins, 1985). Many sources of strain such as tension, anxiety, fatigue, depression, apathy, and irritability are prevalent in dual-career families (Rice).

The effect of wives' employment on husbands' job and life satisfaction has also been examined (Staines, Pottick, \& Fudge, 1986). Staines et al. have found a negative association between wives' employment and husbands' job and life satisfaction. This correlation was attributed to working wives' husbands feeling less adequate as family breadwinners than did the husbands of housewives. Individuals' 
self-image may influence individuals' level of job and life satisfaction. Factors such as job and life satisfaction may also influence individuals' level of work involvement and family involvement.

Although dual-career families represent a high-stress lifestyle (Rice, 1979), there are also increased benefits and satisfactions associated with this lifestyle (Greenhaus et al., 1989). In dual-career families the benefits of their relationship include cooperation and a willingness to work through issues and problems, which increase their marital satisfaction (Gupta \& Jenkins, 1985). There is evidence that the family, and particularly the spouse/partner, provides a buffer to the pressures that arise in the work and family domains (Cooke \& Rousseau, 1984; Kopelman, Greenhaus, \& Connolly, 1983). For example, this may be demonstrated in dual-career couples where the male has profeminist attitudes and is more adaptive than males with traditional attitudes in facilitating the female's career (Greenhaus \& Beutell, 1985). The adoption of a dual-career lifestyle involves a greater departure from social and marital role patterning for a woman than for a man (Rice, 1979). For example, women may benefit from increased social support through the development of their careers. Mediators of health outcomes, such as social support from co-workers and supervisors, have been linked to beneficial health effects of employment for single women (Repetti, Matthews, \& Waldron, 1989).

Many important research questions in regard to the dual-career family have been left unanswered, because most of the research has focused only on the female or has included only married couples in the sample. For example, only one study (Yogev \& Brett, 1985) using dual-career families has taken into account the different 
involvement patterns for couples that result in symmetric or asymmetric levels of work involvement and family involvement. The relationship between work involvement and family involvement and work-family conflict needs to be examined within the context of a general model examining both work and family variables. Work-Family Conflict

Work-family conflict refers to the form of interrole conflict used to describe the conflict that arises from mutually incompatible role pressures in the work and family domains (Greenhaus \& Beutell, 1985). Although many researchers distinguish among work conflict (the extent to which a person experiences incompatible role pressures within the work sphere), family conflict (the extent to which a person experiences incompatible role pressures within the family sphere), and work-family conflict, it is the latter form of conflict (work-family) that was examined in the present study. Before discussing the conceptualization of work-family conflict, work conflict and family conflict will be operationalized. Kopelman et al. (1983) assessed work conflict with items similar to the following: "At work I am not able to be myself" and "At work I receive incompatible requests from two or more people". Family conflict relates to both marital and parental roles: "My family responsibilities force me to do things I would rather not do" and "My spouse and I have different goals for us as a couple" (Kopelman et al.).

Work-family conflict can arise from pressures originating in the work domain and/or pressures originating in the family domain. Greenhaus and Beutell's (1985) review of the sources of conflict between work and family roles was limited to studies 
focusing on the impact of the work role on the family role, a limitation shared by most of the studies on work-family issues (Duxbury \& Higgins, 1991). From their review of the empirical literature, Greenhaus and Beutell presented a number of hypotheses regarding work-family conflict such as the following: simultaneous pressures from both work and family roles are necessary to arouse work-family conflict; role salience (i.e, role involvement) is positively related to the level of work-family conflict; work-family conflict is highest when there are negative sanctions for noncompliance with role demands; support from significant others is related to work-family conflict.

There are three types of work-family conflict: 1) behavior-based conflict, 2) time-based conflict, and 3) straiṇ-based conflict (Greenhaus \& Beutell, 1985). Behavior-based conflict is defined as specific behaviors required in one role that are incompatible with the behavior expectations in the other role (Greenhaus \& Beutell). There is little empirical research assessing the prevalence of behavior-based conflict. Individuals' behaviors that are functional in one role may be considered dysfunctional in another role. According to Greenhaus and Beutell, if individuals are unable to modify their behavior to conform to the expectations of the different roles, then they are likely to experience conflict between the roles. Those spouses/partners who give no social support to their families, which in the opinion of the writer is a dysfunctional role behavior, may increase the work-family conflict experienced by their spouse. Although it would be interesting to examine patterns of behaviors where emotional restraint is typically reinforced at work while openness is expected by 
family members, behavior-based conflict is difficult to measure and is beyond the scope of this study.

The present study focused on time-based conflict and strain-based conflict to assess the level of work-family conflict. Time-based conflict is defined as the time devoted to one role which makes it difficult to participate in the other role (Greenhaus \& Beutell, 1985). Time-based conflict is a result of multiple roles competing for individuals' time, since time spent on activities within one role generally cannot be devoted to activities within another role. Work schedules, work orientation, marriage, children, elderly dependents, and spouse employment all create pressures to participate in either the work role or the family role (Greenhaus \& Beutell). Greenhaus and Beutell maintain that work-family conflict results when the time pressures from one role domain are incompatible with the time demands of the other role domain.

Strain-based conflict is defined as strain symptoms experienced in one role which intrude into the other role and interfere with participation in that role (Greenhaus \& Beutell, 1985). Both work and family stressors can be manifested in strain symptoms such as tension, anxiety, fatigue, depression, apathy, and irritability. Strain is a consequence of the conflict between roles, and it increases individuals' levels of stress. Greenhaus and Beutell have suggested that both time-based conflict and strain-based conflict may positively affect work-family conflict. Work-family conflict can arise from pressures stemming from work and/or the family, which affect individuals' time involvement and/or strain. Time-based conflict and strain-based 
conflict are useful in conceptualizing work-family conflict and thus were considered in the measurement of work-family conflict in the present study.

The original measure of work-family conflict developed by Kopelman et al. (1983) measured both time-based conflict and strain-based conflict. A more recent study by Greenhaus et al. (1989) on the sources of work-family conflict among dual-career couples utilized the Kopelman et al. work-family conflict scale to assess the prevalence of time-based conflict and strain-based conflict. Greenhaus et al. examined the relationship between four types of work domain pressures and two forms of work-family conflict (time-based and strain-based conflict) and the interaction between the partners' level of work salience and the perceived level of work-family conflict. The four types of work domain pressures examined in the Greenhaus et al. study were: 1) work role stressors (role conflict, role ambiguity, and role overload); 2) task characteristics (variety, autonomy, and complexity); 3) work schedule characteristics (work schedule inflexibility, and work-related travel); and 4) work salience (importance of the work role, as measured by the level of work involvement and the priority attached to each spouse/partner's career) (Greenhaus et al.). The inclusion of a wide variety of work pressures facilitated the assessment of unique variance in work-family conflict explained by each work domain pressure. The interaction of the participants' work roles with those of their partners was examined for levels of work salience and work-family conflict.

The dual-career couples employed in the Greenhaus et al. study (1989) were defined as two partners who are members of the work force, and who share a 
common residence. There were 119 couples who completed survey questionnaires anonymously. The participants were characterized as a group of highly educated men and women largely employed full-time in a wide variety of business and professional careers. Men reported experiencing higher levels of time-based conflict than women, but no gender differences were observed for strain-based conflict (Greenhaus et al.). Compared to the women, men had longer job tenure; higher levels of work involvement, task complexity, task variety, and role conflict; traveled more extensively; had more control over their work schedules; and placed a higher priority on their own careers compared to their partner's career (Greenhaus et al.).

High levels of time-based conflict experienced by women were predicted by high work involvement, whereas role ambiguity was a stronger predictor of time-based conflict for men (Greenhaus et al., 1989). Significant predictors of strain-based conflict for women were work involvement and two of the role stressors (role overload and role conflict) while only the role stressors (role ambiguity and role overload) made the most pronounced contribution to strain-based conflict experienced by men. Multiple regression analyses were conducted to compute the interactions between partners' work salience and work-family conflict. Although no interactions were significant for the women, for the men, partners' work involvement interacted with their work involvement to predict men's level of time-based conflict; partners' career priority interacted with the other partner's career priority to predict men's level of strain-based conflict (Greenhaus et al.). 
In previous research, the presence of children in the household has also been found to be related to work-family conflict (Goff et al., 1990). Parents experience work-family conflict more often than non-parents; having more children at home is a source of conflict, and parents of younger children experience more conflict than do parents of older children (Goff et al.; Greenhaus \& Beutell, 1985). There has been an increase in the number of women in the work force who have young children. For example, according to the U.S. Department of Labor (1987), more than half of all children under age 6 had mothers in the work force in March, 1987 compared to 38\% in 1977. Large families, which are characteristically more demanding than small families, also have been associated with high levels of work-family conflict (Goff et al.; Greenhaus \& Beutell). Family-related sources of strain, conflict, and absence of support from the spouse/partner contribute to work-family conflict for the other spouse/partner (Greenhaus \& Beutell). The old models of coordinating work and family life are inappropriate for a majority of the work force, due to the increase in the number of families with working parents.

There also has been an increase in the number of families that are involved in caregiving to their elderly relatives. Caregiving to the elderly has been examined as a burden (Zarit, Orr, \& Zarit, 1985), but it is becoming evident that there are both positive and negative consequences associated with caregiving (Kahana \& Young, 1990). Researchers have suggested that caregiving relationships involving adult children caring for parents are more problematic for all parties involved, than are spouse caregiving relationships (Kahana \& Young). Therefore, it is expected that in 
the dual-career families with an elderly relative, there may be additional responsibilities associated with these family roles. The increased family involvement may lead to higher levels of work-family conflict.

Antecedents of work-family conflict (e.g., work-setting characteristics, work and non-work stressors) and consequences of work-family conflict (e.g., work alienation, job dissatisfaction, poor physical health, and life style changes) were considered in a study by Burke (1988). The study utilized 828 men and women in police work and found that, in general, demographic characteristics such as gender were weakly related to work-family conflict. The research model employed in this study presumed that work-family conflict leads to lower job satisfaction and greater psychosomatic symptoms, and that work-family conflict is caused by events in both work and family domains. There were two significant findings: married individuals reported higher work-family conflict, and individuals with Type A characteristics reported higher work-family conflict (Burke). Police officers who were on shift-work reported greater work-family conflict than officers who worked a regular schedule, which indicated time-based conflict. The work-related variables (work setting characteristics, perceived work stressors) were more strongly related to work-family conflict than were non-work variables (non-work stressors). Burke found that work-family conflict leads to negative outcomes such as lower job satisfaction and reduced physical health, which is consistent with previously reported (Greenhaus \& Beutell, 1985) results of the adverse consequences of work-family conflict. 
It should be noted once again that much of the literature on work-family conflict has focused on the conflict or interference of work on the family, and not vice versa. Rarely have the joint effects of specific work and family pressures been studied (Greenhaus \& Beutell, 1985). The present study examines pressures in dual-career families arising at work which affect the family domain, as well as pressures arising in the family which affect the work domain.

\section{Work Involvement and Family Involvement}

Work involvement and family involvement are conceptualized as individuals' behavioral and psychological responses to their work and family lives. Work involvement and family involvement can be defined by the degree to which individuals identify psychologically with their roles (i.e., as an employee, as a spouse/partner, and if applicable, as a parent) (Duxbury \& Higgins, 1991). Lamb, Chase-Lansdale, and Owen (1979) have operationalized involvement as the values individuals place on being a spouse/partner, on being a parent, and on their work. One source of role pressure is saliency or centrality of a role for one's self-concept (Greenhaus \& Beutell, 1985).

The measurement of work involvement and family involvement can be subjective (psychological attachment) (Quinn \& Staines, 1979) and may also be objective (i.e., number of hours worked). However, it is difficult to collect valid objective data on hours spent in all activities (e.g., time spent eating, sleeping, travelling, etc.). Therefore, for the present study, objective data on both work involvement and family involvement were obtained for descriptive purposes but were not included in the 
analysis. Lodahl and Kejner's (1965) model of work involvement incorporates individuals' psychological response to their work, the degree to which individuals identify with their work, and the relative importance of work to individuals' self-image and self-concept. Lodahl and Kejner's definition of work involvement has been incorporated by other researchers (Goff \& Mount, 1992; Quinn \& Staines, 1979; Yogev \& Brett, 1985). However, the concept of family involvement does not have a comparable research history. The model of family involvement utilized in the Yogev and Brett study incorporated the degree to which individuals identify with their family, the relative importance of the family to individuals' self-image and self-concept, and individuals' commitment to their family. High levels of family involvement are positively related to the number of hours spent in family activities (Greenhaus \& Beutell, 1985). Furthermore, Greenhaus and Beutell have linked the number of hours spent in both work and family activities to increased levels of work-family conflict.

Although there has been a major increase in the number of married women in the work force, there has not been a corresponding increase in the husbands' involvement in family roles (DiBenedetto \& Tittle, 1990; Duxbury \& Higgins, 1991). Studies have shown that women's and men's roles in the family are relatively slow to change, since women still have the primary responsibility for the family even though they are employed outside the home (DiBenedetto \& Tittle). There is a lag between behaviors in marital roles and shifts in women's actual roles in the occupational world (DiBenedetto \& Tittle; Rapoport \& Rapoport, 1976). Duxbury and Higgins have 
found that family conflict is a stronger predictor of work-family conflict among women than among men. Work schedules and work demands make it more difficult for a woman to perform her family duties and may thus increase her level of work-family conflict (Duxbury \& Higgins). The gender differences observed in the Duxbury and Higgins study on work-family conflict support the view that there have been few changes in society's perceptions of work- and family-role responsibilities over the last two decades. Rapoport and Rapoport reported a "psychological lag" between the changes occurring for men and women in the world of work and in the world of family. However, the majority of Americans believe that both parents should share child rearing responsibilities and also "approve" of wives working (DiBenedetto \& Tittle). For many women, increased involvement in the macrosocial world of work is not paralleled by their spouse/partner's increased involvement in the microsocial world of the family.

Perhaps the lag in the redistribution of roles between men and women partly exists due to societal expectations. That is, males and females are expected to have different levels of involvement in their work and family domains (e.g., traditionally males have high work involvement; females have high family involvement). Some males may still be reluctant to take on additional child care and household responsibilities. This may be related to findings which indicate that both males and females place a higher priority on the male's career than on the female's career (Greenhaus et al., 1989). Thus, it is seen as legitimate for males to place a high priority on their own career, which may distract them from their family involvement. 
Family roles may simultaneously reduce the effects of work stressors and serve as a source of stress for employed individuals (Cooke \& Rousseau, 1984). There are expectations that are inherent in work and family roles that can lead to physical and psychological strain. The expectations and pressures associated with both these roles can generate interrole conflict when they dominate the time of the focal person and interfere with fulfilling the expectations associated with the other role (Cooke \& Rousseau). The individual's level of involvement may increase or decrease in work or family roles over time. For example, the demands to work more hours or to work on weekends and holidays create stress that can be reduced by allocating more time to work-related activities (Cooke \& Rousseau). If individuals experience stress at work because they have a deadline that has not been met, then they can reduce their level of stress by spending time working on completing the task. However, this coping strategy becomes increasingly difficult as more family members are added and family expectations multiply (Cooke \& Rousseau). Similarly, it is expected that the pressures to increase family involvement may be reduced by allocating more time to family-related activities.

As demands of the work or family roles increase, interrole conflict is prone to increase. In the 1977 Quality of Employment Survey (Quinn \& Staines, 1979), it was found that conflict can arise when pressures to expand individuals' work activities go beyond the normal working day. That is, a significant number of respondents cited problems with excessive hours $(8.2 \%)$, overtime $(10.5 \%)$, and work schedules (26.7\%) that interfere with family life. Thus, work involvement and family 
involvement is related to work-family conflict as measured by subjective reactions to involvement and the number of hours spent in work and family activities.

\section{Relationship Between Work Involvement and Family Involvement and}

\section{Work-Family Conflict}

Pressures to become involved in work or family roles can increase the likelihood of work-family conflict (Cooke \& Rousseau, 1984; Greenhaus \& Beutell, 1985). When there are high levels of involvement in one role, there may be a corresponding increase in the amount of time attached to that role which makes it more difficult to conform to the expectations associated with the second role (Greenhaus \& Beutell). High levels of work involvement and family involvement are positively related to the number of hours spent in work and family activities (Greenhaus \& Beutell). Also, high involvement in one role may be associated with an increase in the amount of time and effort devoted to that role (Frone, Russell, \& Cooper, 1992). Individuals may be mentally preoccupied with one role even when they are physically attempting to meet the demands of a second role (Frone \& Rice, 1987; Frone et al., 1992).

The recent study by Frone, Russell, and Cooper (1992) proposed a comprehensive model of the work-family interface and specifically distinguished between work interfering with family (Work -> Family conflict) and family interfering with work (Family $->$ Work conflict). By testing the antecedents and outcomes of both forms of work-family conflict separately, they were able to examine a reciprocal relationship between the types of conflict (Frone et al.). The participants in the study consisted of a random sample of 631 subjects who were interviewed in 
their homes by the researchers. The selection criteria produced a sample of individuals who were employed at least 20 hours per week, currently married or living as married, and had children living at home. Scales were used to measure work involvement (utilizing the Lodahl and Kejner (1965) work involvement scale), family involvement (which was assessed by modifying the work involvement scale to refer to the respondent's spouse or child(ren)), job stressors, family stressors, job distress, family distress, and work-family conflict (four items from the Kopelman et al. (1983) work-family conflict scale). Two of the work-family conflict items assessed the degree to which individuals' work interferes with their family life (Work - > Family) and two of the items assessed the degree to which individuals' family life interferes with their work (Family -> Work) (Frone et al.).

As hypothesized, the Frone, Russell, and Cooper (1992) study revealed a reciprocal relationship between Work -> Family conflict and Family -> Work conflict. That is, work interferes with family demands and family interferes with work demands. Job stressors were positively related to Work $->$ Family conflict; family stressors and family involvement were positively related to Family - > Work conflict (Frone et al.). The relationship between work involvement and Work -> Family conflict was moderated by job type. Work involvement was positively related to Work -> Family conflict for white-collar workers, and work involvement was unrelated to Work -> Family conflict among the blue-collar workers (Frone et al.). Although the Frone et al. study examined both Work -> Family conflict and Family -> Work conflict, their measure of work-family conflict 
is conceptually different from the measurement of work-family conflict that will be employed in the present study. For the present study, the work-family conflict scale was bidirectional and simultaneously assessed the interference of work on the family domain and the interference of family on the work domain.

Based on their review of the literature on work-family conflict, Greenhaus and Beutell (1985) suggested that a positive relationship between work involvement and work-family conflict exists. A possible explanation for this relationship is that individuals who are highly involved with work or family activities or both have high work-family boundary permeability (Hall \& Richter, 1988). Individuals experience high boundary permeability when the demands of one domain intrude into the other domain. This in turn, may increase work-family conflict. The positive relationship between work involvement and work-family conflict also could be linked to the fact that individuals with higher levels of work involvement may feel that there are no legitimate claims on their time and energy other than their work, which may increase the potential for work-family conflict for their spouse/partner (Ridley, 1973). This may also be the case for individuals with higher levels of family involvement who feel that family activities are legitimate demands of their time and energy.

Frone and Rice (1987) examined whether family involvement moderated the relationship between work involvement and work-family conflict. Their questionnaire measured two types of family involvement (spouse involvement and parent involvement) and two types of work-family conflict (work-spouse conflict and work-parent conflict). The spouse involvement items assessed the degree of 
involvement with one's spouse (e.g., "The most important things that happen to me involve my role as a spouse"). The parental involvement items assessed the degree of involvement with one's child or children with similarly worded items that made reference to children and the parental role. The measure of work-family conflict was examined through work and spouse roles and work and parental roles by asking respondents to indicate how much internal conflict each situation presented for them. For example, work-spouse conflict was assessed by items such as: "Feeling it is more important for your spouse to succeed versus feeling it is more important for you to succeed in your work"; work-parent conflict was assessed by items such as: "Devoting a large percentage of your time to raising your family versus devoting a large percentage of your time to work." Frone and Rice found that work involvement and work-spouse conflict were positively related for individuals high in spouse involvement and were unrelated for individuals low in spouse involvement. However, parental involvement did not moderate the relationship between work involvement and work-parent conflict. Work involvement was positively related to work-parent conflict.

Pleck (1977) has suggested that the psychological involvement in a role acts as a sensitizer to the interference effects, which make individuals more aware of problems within that role. The increased awareness that is created serves to increase individuals' perceived level of role conflict. The present study obtained both subjective and objective measures of involvement to incorporate both the role salience and the number of hours spent in work and family roles. However, only the 
subjective measures of involvement were used in the data analysis. If individuals perceive that they are highly involved in their work role and are preoccupied with their work role, then their perceived level of work-family conflict may be elevated.

Greenhaus and Beutell (1985) have proposed that role salience (operationalized as work involvement and family involvement) is positively related to the level of work-family conflict and that role salience moderates the relationship between externally-produced pressures and work-family conflict. Goff and Mount (1992) state that the proposition of role salience as a moderator assumes that individuals for whom a role is highly salient are particularly responsive to environmental pressures that arise within the role and experience more work-family conflict due to intra-role pressures than do individuals who are less involved in their role. Goff and Mount tested the proposition of Greenhaus and Beutell by hypothesizing a statistical interaction between work involvement and work role pressures (role conflict, role overload, role clarity, and control over work hours). Work role pressures were expected to be related to a higher level of work-family conflict among individuals with high levels of work involvement than among individuals who were not highly involved in their work.

Goff and Mount's (1992) study revealed a statistically significant difference between men and women on role conflict which was measured by respondents' level of agreement with two items (e.g., On my job, I can't satisfy everybody at the same time). Men reported more role conflict than women. Among both males and females, work involvement and all the work-related pressures were positively related 
to work-family conflict. For females there was not a significant interaction between work involvement and any of the work role pressures; for males, only the interaction between work involvement and role clarity was significant. The male and female participants in this study did not differ in their average levels of work involvement or work-family conflict. The proposed hypothesis of a statistical interaction between work involvement and work role pressures was not supported among women and was only marginally supported for men. Although this study provided support for the positive correlation between work involvement and work-family conflict, it did not examine the impact of family involvement on work-family conflict. 


\section{Description of the Problem}

\section{$\underline{\text { Rationale for Study }}$}

The area of work-family conflict is important to organizations, as well as to employees, because conflict, as a source of stress, is associated with negative consequences both on and off the job (Duxbury \& Higgins, 1991). The potential negative consequences of work-family conflict include increased health risks, poorer performance in the parenting role, decreased productivity, tardiness, absenteeism, turnover, poor morale, reduced life satisfaction, and lower mental health (Duxbury \& Higgins). Furthermore, dual-carreer issues can lead to problems for organizations in recruiting qualified employees, in the retention of employees on a long-term basis, and problems in maximizing performance (Gupta \& Jenkins, 1985). Therefore, organizations need to pay more attention to issues related to balancing work and family roles among dual-career families.

It has been suggested that a new pattern in dual-career couples is emerging that is characterized by parents sharing responsibilities for children and the household (Rice, 1979). In some families where the female is primarily responsible for the family needs, when the female begins to work or returns to work, the responsibility for performing the household duties shifts to other members of the family. Thus, there may be a major impact on the male's involvement with children (if applicable) and household duties. The increased demands associated with the dual-career family 
require that these couples balance the spheres of work and family. However, Duxbury and Higgins (1991) found that the redistribution of roles within the family, to compensate for women's increased role responsibilities outside the home, has not yet occurred among dual-career families. Perhaps this is related to the view that high involvement in nontraditional work or family roles may be difficult for men and women if they are not socially supported for their involvement in these roles (Duxbury \& Higgins).

Furthermore, Duxbury and Higgins (1991) suggested that the gender differences in antecedents and consequences of work-family conflict experienced by parents in dual-career families were attributed to societal expectations and behavioral norms that people experience in their various roles. Men and women may have different coping mechanisms to deal with stressful conditions within the work and family domains. For example, Duxbury and Higgins have suggested that men may be socialized to deal effectively with stressors in the work domain, while females may be socialized to deal effectively with stressors in the family domain. Of course, men and women may be able to cope with the demands from both the work and family domains equally well.

Adjustments in the work-family role system are needed to change traditional views of work and family roles so that individuals' involvement in both roles may be enhanced. For example, families should support both males and females spending energy on the work domain and the family domain. A breakdown of occupational sex-segregation is another aspect of the fundamental changes required in work roles for both sexes (Lobel, 1991). Greater balance and sharing in work and family roles 
within dual-career families requires the utilization of work-family conflict models that include measures of both work involvement and family involvement.

Work involvement has primarily been studied as an antecedent (Frone et al., 1992; Greenhaus et al., 1989) of the relationship between work-family conflict and work role pressures. There has been a growing research interest in the direct effects of work-related pressures and work involvement on work-family conflict, and in research focusing on gender differences in work-family conflict. More recently work involvement has been studied as a moderator of the relationship between work-family conflict and work role pressures (Goff \& Mount, 1992). Previous research has not focused on the relationship between both work involvement and family involvement in dual-career families and on a partner's level of work-family conflict. However, relationships between work involvement and work-family conflict (Greenhaus et al.), between work involvement and work conflict, and between family involvement and family conflict (Higgins et al., 1992) have been examined separately. The present study is unique in that it explores the extent to which one's spouse's level of work and family involvement predicts an individual's work-family conflict. Also, the spouse sociodemographic variables are taken into account in order to examine their effect on one's spouse's work-family conflict. The relationship between spouses' work and family involvement and individuals' work-family conflict has not been clearly delineated. Dual-career families are the ideal population to explore these work and family issues because both partners are members of a family and are employed. 
Therefore, the present study examined these relationships in the context of dual-career families.

\section{Hypotheses}

The present research examined the relationship between work involvement and family involvement and work-family conflict in couples in dual-career families. The following hypotheses were examined:

Hypothesis 1: Work-family conflict (WFC) will be predicted by work involvement (WI) across study participants. WI-- > WFC

This is a replication of previous research by Duxbury and Higgins (1991) and others. Individuals with higher levels of work involvement, who are preoccupied with their work, are likely to devote increased effort and energy to the work role, which will result in increased pressures from the work domain and higher levels of work-family conflict (Greenhaus et al., 1989). High levels of involvement are positively related to the number of hours spent in work and family activities (Greenhaus \& Beutell, 1985). Greenhaus and Beutell have linked the number of hours spent in both activities to increased leveis of work-family conflict. Frone and Rice (1987) have also reported positive relationships between work involvement and work-family conflict.

Hypothesis 2: Work-family conflict (WFC) will be predicted by family involvement (FI) across study participants. FI-- > WFC

Although researchers have found a positive relationship between family involvement and family conflict (Greenhaus \& Kopelman, 1981), the relationship 
between family involvement and work-family conflict is less well documented. This may be due, in part, to the focus of research on "work" involvement and work-family conflict, rather than "family" involvement. Individuals who are highly involved in their family roles may spend a large percentage of their time on family and household activities. They may experience more interruptions at work for family issues and the pressures arising from their family may lead to higher levels of work-family conflict. Duxbury and Higgins (1991) found a positive relationship between family involvement and work-family conflict, a relationship that was stronger in the male subjects than the females. Greenhaus and Beutell (1985) have linked the number of hours spent in family activities, as well as work activities, to increased levels of work-family conflict.

Hypothesis 3: An individual's work-family conflict will be predicted by his/her spouse's work involvement (Employee: E, and Spouse: S). EWI- > SWFC and SWI-- > EWFC

Work-family conflict experienced by couples in a dual-career relationship may be influenced by the interaction of their own work roles with those of their partner's (Gupta \& Jenkins, 1985). Employees whose partners display a high level of work involvement are likely to experience intensified family pressures (Greenhaus et al., 1989). For example, an individual who is highly involved in work is likely to devote considerable time, effort, and energy to his/her work and thereby have less time and energy to participate in family activities. This may, in turn, increase their spouse's level of work-family conflict. 
Greenhaus and Kopelman (1981) found that men experienced more intense work-family conflict when their partners held managerial or professional jobs (which require high levels of work involvement), than when their partners held nonmanagerial or nonprofessional jobs. A man's work involvement is viewed as consistent with his primary role as breadwinner, and there is little contradiction between societal role expectations and involvement (Duxbury \& Higgins, 1991). Individuals with higher levels of work involvement may or may not reduce the number of hours spent on family activities. The partners of those individuals who are less involved in their families may experience higher levels of work-family conflict due to the additional family responsibilities they take on (Greenhaus et al., 1989). Greenhaus et al. found that an individual's levels of work salience (work stressors, tasks, importance of role) were unrelated to his/her level of work-family conflict, but that the interaction of one's work salience and one's spouse's work salience predicted individual's work-family conflict. It is expected that in general, individuals who have partners with high levels of work involvement may experience higher levels of workfamily conflict than individuals with partners who are less involved with their work.

Hypothesis 4: An individual's work-family conflict will be predicted by his/her spouse's family involvement (Employee: E, and Spouse: S). EFI-- SWFC and SFI-- > EWFC

The relationship between family involvement and work-family conflict has not been clearly established. While marriage can lead to work-family conflict, this conflict and its negative consequences can be reduced by support and other positive 
contributions a spouse/partner can provide (Cooke \& Rousseau, 1984). There is evidence that suggests that the family, particularly the spouse or partner, provides a buffer against pressures that arise in the work and family spheres (Kopelman et al., 1983). If individuals are highly involved in their family, then their partners may not devote as much time and energy toward child care and household tasks. Fewer demands may be placed on those individuals with partners who are primarily responsible for their family needs, which allows those individuals more time to spend on their work or personal interests. Therefore, individuals who are highly involved in their family may have partners who experience lower levels of work-family conflict than individuals with low levels of family involvement.

Hypothesis 5: Work-family conflict will be predicted by the number of dependents (children and elderly) living at home. \#DEP--> WFC

The present study examined the variable "dependents" as defined by the number of children and elderly relatives living at home. The author realizes that many people may experience significant caregiving responsibilities to elderly relatives even though they may not live in the same household. However, for the purpose of the study, couples' dependents were limited to those individuals residing in the same household.

It has been suggested that parents experience work-family conflict more often than non-parents and that the number of children at home can influence the degree of work-family conflict experienced by the parents (Cooke \& Rousseau, 1984; Goff et al.; Greenhaus \& Beutell, 1985). Also, it has been demonstrated that parents of younger children experience more conflict than do parents of older children due to 
their younger children's needs (Cooke \& Rousseau). Although the presence of children in the household is related to increased levels of work-family conflict (Goff et al., 1990), the presence of elderly dependents has not been examined within the context of dual-career families. It has been established that in elderly caregiving relationships, the adult child (who is more often female) experiences more problems in the role of caregiver than the spouse does (Kahana \& Young, 1990). Dual-career couples who have children and are also responsible for an elderly relative may experience higher levels of work-family conflict due to the additional demands on their family roles. Therefore, the effects of the total number of dependents on workfamily conflict will be examined.

Hypothesis 6: Work-family conflict will be higher for females than for males. FWFC > MWFC

Gender differences in males' and females' levels of work-family conflict may exist for a number of reasons. Although there has been an increase in the number of women in the work force, there has not been a corresponding increase in men's involvement in family roles (DiBenedetto \& Tittle, 1990; Duxbury \& Higgins, 1991). For the most part, women still have the primary responsibility for children and the household (DiBenedetto \& Tittle; Duxbury \& Higgins; Rapoport \& Rapoport, 1971). Furthermore, researchers have suggested that behavior in work and family roles may influenced by societal norms (Duxbury \& Higgins).

The study by Duxbury and Higgins (1991) demonstrated that the tie between family expectations and work-family conflict was independent of gender. Family 
expectations had a similar effect on men and women, and they both experienced the same degree of difficulty in balancing work and family demands. However, the researchers supported their hypothesis that family conflict was a stronger predictor of work-family conflict among women than among men. For women, extensive involvement in work may arouse anxiety and guilt regarding their lack of participation in their family. Work schedules and work demands make it more difficult for a woman to maintain her family activities and may increase her level of work-family conflict. However, the men and women in the Duxbury and Higgins study experienced similar levels of work-family conflict. The observed gender differences in the antecedents and consequences of work-family conflict were attributed to societal expectations and behavioral norms regarding traditional sex roles.

The Greenhaus et al. (1989) study found that work involvement was a stronger predictor of time-based conflict for women than men. Women may experience higher levels of time-based conflict and strain-based conflict due to greater demands on their time and energy (Greenhaus \& Beutell, 1985). Pleck (1977) suggested that men apparently do not experience as much work-family conflict as females do, because in general they have fewer child care and household tasks to perform. Both men and women experienced similar levels of strain-based conflict and gender differences in time-based conflict diminished after demographic and work role characteristics were statistically controlled. However, in the present study it is proposed that the women 
will experience higher levels of work-family conflict than the men, based on the assumption that women often have more family responsibilities than men do.

Hypothesis 7: If the spouses/partners are symmetric in both work involvement and family involvement (i.e., have the same level of involvement in both work and family), their level of work-family conflict will be lower than the level of workfamily conflict experienced by couples with other involvement patterns (i.e. symmetric work-asymmetric family, asymmetric work-symmetric family, and asymmetric in both work and family).

Although four different patterns of couples based on the similarity of their work involvement and family involvement have been identified (Yogev \& Brett, 1985), the relationship between couples' involvement patterns and work-family conflict has not been examined. Therefore, this hypothesis is exploratory.

According to Yogev and Brett (1985), the fact that some couples are not similarly involved in their work and family roles may be due to socialization of traditional sex role stereotypes which influence the stereotyping that currently exists in society. Furthermore, work involvement between partners is often asymmetric because of the different types of jobs held by men and women. In cases where women hold lower status jobs, high work involvement is often not a characteristic of the job. However, when females hold higher status jobs, they experience higher levels of work involvement.

In couples with symmetric work and family involvement patterns (i.e., both partners/spouses are similarly involved in work and family activities) there may be 
less work-family conflict experienced by the couple. There are increased benefits, such as greater marital satisfaction, which are associated with couples who are similarly involved in their families (Yogev \& Brett, 1985). Perhaps, the combination of two partners who are simultaneously involved in work and family activities and who are comparable in their level of work involvement and family involvement, encourages the couple to meet the conflicting demands that arise in the work and family domain. Of course, most couples may attempt to balance the conflicting demands of their work and family lives in order to maintain a healthy relationship.

It appears that when dual-career couples are both similarly involved in their work and family there will be lower levels of work-family conflict. For example, Yogev and Brett (1985) have suggested that an individual's orientation toward family involvement may change to be more like his or her partner's in order to lessen tension or conflict and restore balance in the relationship. Couples who are similarly involved in their work and family may understand each other's needs and may be supportive of one another, resulting in lower levels of work-family conflict.

Hypotheses 8 through Hypothesis 11 were exploratory since the number of dependents (children and elderly living at home) and age of youngest child have been examined as a predictors of work-family conflict, but have not been examined as moderating variables of the relationship between work involvement and family involvement and work-family conflict. 
Hypothesis 8: The relationship between work involvement and work-family conflict will be moderated by the number of dependents (children and elderly) living at home. WI X \#DEP-- > WFC

Hypothesis 9: The relationship between family involvement and work-family conflict will be moderated by the number of dependents (children and elderly) living at home. FI X \#DEP-- > WFC

Hypothesis 10: The relationship between work involvement and work-family conflict will be moderated by age of youngest (or only) child. WI X AGE--> WFC

Hypothesis 11: The relationship between family involvement and work-family conflict will be moderated by age of youngest (or only) child. FI X AGE--> WFC

The number of dependents living with the dual-career couple may significantly affect how each partner allocates his/her time to his/her work and family domains. Similarly, age of youngest child (or only child) may have a significant effect on the relationship between work involvement and work-family conflict and family involvement and work-family conflict. Parenthood is associated with psychological symptoms of strain, and this strain is intensified when younger children (under six years old) are present (Cooke \& Rousseau, 1984) because younger children are likely to place greater demands upon their parents than do older children. 
Method

\section{$\underline{\text { Respondents }}$}

The present study consisted of 436 couples ( 436 females; 436 males; $N=872$ ) who were partners in a dual-career relationship. The participants were recruited through a bank organization in the Northwest United States. The present study was conducted as part of a larger research project which sent surveys to a stratified random sample of 2000 bank employees. The criteria for participation in the present study were as follows: a) at least one partner was a bank employee; b) both partners were employed for at least 20 hours per week; c) the couple had to share a common residence, although they did not have to be married to be included in the sample; d) the couple must have been married or living together for a minimum of three years. Among the bank employees, the response rate was $50 \%$ of those surveyed, of which $75 \%$ were married or living with their partners.

\section{Instrument}

A survey questionnaire was administered to assess sociodemographic information, work involvement and family involvement, and the level of work-family conflict for each employee and his/her respective spouse/partner (see Appendix).

Sociodemographic Data. Sociodemographic information was collected, including age, sex, ethnic background, marital status, number of years married or living together, number and age of children, and total number of dependents (includes 
children and elderly living at home). Information on job classification, tenure, job flexibility, number of hours regularly worked per week, number of hours of overtime, and work schedules was obtained.

Work Involvement and Family Involvement. Work involvement (Items 25, 26, 30,31 ) and family involvement (Items $27-29,32$ ) were assessed using modified involvement measures developed by Quinn and Staines (1979). These eight items measuring subjective involvement used a 5-point Likert scale response format anchored by strongly disagree to strongly agree. Three subjective items on work involvement were modified from the work involvement scale used by Quinn and Staines (internal consistency reliability estimate $=.56$ ), two of the three items on family involvement were modified from Quinn and Staines, and one family involvement item was modified from a Quinn and Staines work involvement question to refer to family (My main satisfaction in life comes from my family). In order to increase the internal consistency reliability estimates, two subjective items were added. These two items were modified from an item in Lodahl and Kejner's (1965) work involvement scale to reflect both involvement with work and involvement with family (I live, eat, and breath my work (family/personal life)). 
Work-Family Conflict. The measure of work-family conflict was adapted from Kopelman et al. (1983), and consisted of 16 items (Items 33-48) using a 5-point Likert scale response format (strongly disagree to strongly agree). Eight interrole conflict items from Kopelman et al. measured spillover from work to family, and eight items were included to reflect the inverse: the spillover from family to work. This bidirectional work-family conflict scale was recently employed by Goff et al. (1990). Kopelman et al.'s questionnaire has been successfully used by other researchers to measure time-based conflict and strain-based conflict (Greenhaus et al., 1989). Of the original eight interrole conflict items, two of the items measure time-based conflict (e.g., My work (family) takes up time that I would like to spend with my family (work)), and six of the items measure strain-based conflict (e.g., My family (co-workers) dislikes how often I am preoccupied with my work (family) while I am home (at work)).

\section{Procedure}

The participants who were employed by the bank were given two copies of the survey packets in separate envelopes with matching codes for each member of the couple (employee and his/her respective spouse/partner). The survey respondents were instructed to independently complete the survey either at work or at home and to return it in a sealed envelope to the researcher. Participation in the study was entirely voluntary, and assurances of anonymity were maintained. 


\section{Results}

\section{Descriptive Statistics}

Family Characteristics. The number of survey respondents, and means and standard deviations for family characteristics computed by couples (employee and spouse/partner) can be found in Table I (see Table I). Overall (combined) means and the range for each variable are shown. There was a total of 872 survey respondents (436 females whose average age was 40.6 years and 436 males whose average age was 43.5 years), with an overall average age of 42.0 years. The couples have been married or living together for an average of 15.8 years; have an average of 1 child living at home; the average age of their youngest (or only) child is 0.3 years; the average age of their oldest child is 11.6 years; and have on average $<1$ elderly relative living at home $(1.7 \%$ of the respondents have elderly relatives living at home).

The distribution of family characteristics for survey respondents is shown in Table II (see Table II).

Work Characteristics. The means and standard deviations for work characteristics computed by couples can be found in Table III (see Table III). Overall (combined) means and the range for each variable are shown. The employees have worked an average 11.0 years (tenure) for the bank organization, while their spouses have worked an average 8.5 years in their present job; the couples work an average 
of 41.3 hours weekly (females average 40.7 hours and males average 46.5 hours weekly) and an average 4.8 hours overtime weekly (females average 2.7 hours and males average 6.6 hours overtime weekly). The distribution of work characteristics for survey respondents are shown in Table IV (see Table IV).

Work-Family Measures. The means and standard deviations for the work-family measures computed by couples can be found in Table V (see Table V). The mean for employees' work involvement was 2.5 , and the mean for spouse/partners' work involvement was 2.4 on a scale ranging from Low Involvement/Conflict (1) to High Involvement/Conflict (5). The mean for employees' family involvement was 3.6 compared to 3.9 for spouse/partners' family involvement. The mean for employees' work-family conflict was 3.3 compared to 2.6 for spouse/partners' work-family conflict. Overall means for employee and spouse/partner combined were work involvement (2.4), family involvement (3.7), and work-family conflict (2.6). Although not shown in Table V, the mean for females' work involvement was 2.4 compared to 2.5 for males' work involvement, and the mean for females' family involvement was 3.7 compared to 3.8 for males' family involvement. Also, the mean for females' work-family conflict was 2.7 compared to 2.6 for males' work-family conflict. The internal consistency reliability estimate (Cronbach's Alpha) was .85 for the work-family conflict measure. Cronbach's Alpha was .86 for the work involvement measure and .87 for the family involvement measure. 
Correlation Matrix for Study Variables. Pearson correlation coefficients for the study variables are shown in Table VI (see Table VI). There were 12 study variables included in the correlation matrix. There was a significant positive correlation between work involvement and actual hours worked, between work involvement and number of elderly relatives living at home, and between work involvement and work-family conflict. There was a significant negative correlation between work involvement and number of children living at home, as well as between work involvement and family involvement. There was a significant positive correlation between family involvement and sex, with males having slightly higher levels of family involvement. There was a significant positive correlation between family involvement and number of children, and between family involvement and work-family conflict. There was a significant negative correlation between family involvement and age, between family involvement and years worked (tenure), between family involvement and age of oldest child, and a negative correlation between family involvement and work involvement. There was a significant positive correlation between work-family conflict and actual hours worked, between work-family conflict and number of children, between work-family conflict and work involvement, and between work-family conflict and family involvement. There was a significant negative correlation between work-family conflict and age, between work-family conflict and sex, and between work-family conflict and years married or living together. 


\section{Tests of Hypotheses}

Preliminary analyses using multiple regression techniques revealed that work-family conflict was significantly influenced by the sociodemographic variables (i.e., sex, age, years worked (tenure), number of dependents, and age of youngest (or only) child). Thus, the set of sociodemographic variables that accounted for a significant amount of variance in work-family conflict was controlled for in subsequent analyses. The study variables were entered into three separate regression equations hierarchically, in their assumed order of priority. The increment in $\mathrm{R}^{2}$ associated with each variable or set of variables was examined at each step of the regression equation to determine the unique contribution of that variable or set of variables to work-family conflict (Cohen \& Cohen, 1983).

Overall Work-Family Conflict. Hierarchical multiple regression analysis was conducted to determine the amount of variance accounted for in overall work-family conflict by the study variables to test Hypothesis 1, 2, and 5, and Hypothesis 8 through Hypothesis 11 (see Table VII). After controlling for the sociodemographic variables (age, sex, tenure, number of dependents, and age of youngest (or only) child), the study variables were entered into the regression equation in their assumed order of priority. Since work involvement has been shown to be the most significant predictor of work-family conflict (Duxbury \& Higgins, 1991), work involvement was entered first into the equation to determine if it accounted for a significant amount of variance in work-family conflict above and beyond the sociodemographic variables. A second regression analysis was run using family involvement to determine if family 
involvement accounted for a significant amount of variance in work-family conflict above and beyond the sociodemographic variables. To test Hypothesis 8 and Hypothesis 10, two models were run with the sociodemographic variables, work involvement, and the interaction terms (Work Involvement X Dependents; and Work Involvement X Age Youngest Child) to determine if their products accounted for a significant amount of variance in work-family conflict above and beyond the sociodemographic variables and work involvement. Similarly, to test Hypothesis 9 and Hypothesis 11 , two models were run with the sociodemographic variables, family involvement, and the interaction terms (Family Involvement X Dependents; and Family Involvement X Age Youngest Child) to determine if their products accounted for a significant amount of variance in work-family conflict above and beyond the sociodemographic variables and family involvement.

Results of the hierarchical multiple regression analysis for overall work-family Conflict demonstrated support for $\mathrm{Hl}$ : work involvement was a significant predictor of work-family conflict $\left[\mathrm{E}(6,786)=36.95 ; \mathrm{p} \leq .001 ; \Delta \mathrm{R}^{2}=.04\right] ; \mathrm{H} 2$ : family involvement was a significant predictor of work-family conflict $[\underline{E}(6,786)=5.62$, $\mathrm{p} \leq .05 ; \Delta \mathrm{R}^{2}=.006$ ] (see Table VII); and H5: number of dependents was a significant predictor of work-family conflict $\left[\underline{E}(5,788)=10.85, \mathrm{p} \leq .001 ; \Delta \mathrm{R}^{2}=.009\right]$ (not shown in table).

Hypothesis 8 through Hypothesis 11 were exploratory, since the relationships between work involvement and family involvement and work-family conflict may be moderated by the number of dependents that the couple has identified; and the 
relationships between work involvement and family involvement and work-family conflict may be moderated by age of youngest (or only) child. Multiple regression analysis was used to test the moderating effects of the number of dependents and age of youngest (or only) child on the relationships between work involvement and work-family conflict and family involvement and work-family conflict, as described above (see Table VII). No significant $F$ values $\left(\Delta \mathrm{R}^{2}=.00\right)$ were obtained for the interaction terms (H8: Work Involvement X Dependents; H9: Family Involvement X Dependents; H10: Work Involvement X Age Youngest Child; and H11: Family Involvement X Age Youngest Child). Therefore, the obtained results did not support Hypothesis 8 through Hypothesis 11.

Employee Work-Family Conflict. To test Hypothesis 3 and Hypothesis 4, employee work-family conflict was regressed on spouse work involvement and spouse family involvement (see Table VIII). Employee work-family conflict was regressed on spouse work involvement to determine if these variables accounted for a significant amount of variance in employee work-family conflict above and beyond the spouse sociodemographic variables. A second step to the regression equation was run regressing employee work-family conflict on spouse family involvement. To test Hypothesis 8 and Hypothesis 10, the interaction terms containing spouse work involvement (Spouse Work Involvement X Dependents; and Spouse Work Involvement $\mathrm{X}$ Age Youngest Child) were entered into the regression equation to determine if their products accounted for a significant amount of variance in employee work-family conflict above and beyond the spouse sociodemographic variables and 
spouse work involvement. Similarly, to test Hypothesis 9 and Hypothesis 11, the interaction terms containing spouse family involvement (Spouse Family Involvement X Dependents; and Spouse Family Involvement X Age Youngest Child) were entered into the regression equation to determine if their products accounted for a significant amount of variance in employee work-family conflict above and beyond the spouse sociodemographic variables and spouse family involvement.

The results revealed that the spouse sociodemographic variables (age, sex, tenure, number of dependents, and age of youngest (or only) child) accounted for a significant amount of variance in employee work-family conflict $[E(6,365)=2.77$; $\left.\mathbf{R}^{2}=.036 ; \underline{p}<.05\right]$ (see Table VIII). Results failed to demonstrate that spouse work involvement and spouse family involvement accounted for a significant amount of variance in employee work-family conflict. Also, the results demonstrated that the interaction terms (Spouse Work Involvement X Dependents; Spouse Family Involvement X Dependents; Spouse Work Involvement X Age Youngest Child; and Spouse Family Involvement $X$ Age Youngest Child) did not account for a significant amount of variance in employee work-family conflict. Therefore, the hypotheses that an individual's work-family conflict is predicted by his/her spouse's work involvement (H3) and by his/her spouse's family involvement $(\mathrm{H} 4)$ were not supported.

Spouse Work-Family Conflict. To further test Hypothesis 3 and Hypothesis 4, spouse work-family conflict was regressed on employee work involvement and employee family involvement (see Table IX). Spouse work-family conflict was first regressed on employee work involvement after holding sociodemographic variables 
constant by entering them into the first block. Then spouse work-family conflict was regressed on employee family involvement to determine if this variable accounted for a significant amount of variance in spouse work-family conflict above and beyond the employee sociodemographic variables. To test Hypothesis 8 and Hypothesis 10, the interaction terms containing employee work involvement (Employee Work Involvement X Dependents; and Employee Work Involvement X Age Youngest Child) were entered into the regression equation to determine if their products accounted for a significant amount of variance in spouse work-family conflict above and beyond the employee sociodemographic variables and employee work involvement. Similarly, to test Hypothesis 9 and Hypothesis 11 the interaction terms containing employee family involvement (Employee Family Involvement X Dependents; and Employee Family Involvement $\mathrm{X}$ Age Youngest Child) were entered into the regression equation to determine if their products accounted for a significant amount of variance in spouse work-family conflict above and beyond the employee sociodemographic variables and employee family involvement.

The results revealed that the sociodemographic variables (age, sex, tenure, number of dependents, and age of youngest (or only) child) accounted for a significant amount of variance in spouse work-family conflict $[F(6,365)=4.66$; $\left.\mathrm{R}^{2}=.051 ; \mathrm{p}<.01\right]$ (see Table IX). Results failed to demonstrate that employee work involvement or employee family involvement accounted for a significant amount of variance in spouse work-family conflict. Furthermore, the interaction terms (Employee Work Involvement X Dependents; Employee Family Involvement X 
Dependents; Employee Work Involvement X Age Youngest Child; and Employee Family Involvement X Age Youngest Child) did not account for a significant amount of variance in spouse work-family conflict. Therefore, the hypotheses that an individual's (spouse's) work-family conflict is predicted by his/her spouse's (employee) work involvement $(\mathrm{H} 3)$ and by his/her spouse's (employee) family involvement (H4) were not supported.

Sociodemographic Variables. Results of the hierarchical multiple regression analyses demonstrated that when overall work-family conflict was regressed on the set of sociodemographic variables, sex $(\underline{t}=-1.9 ; \mathrm{p}=.06 ; \beta=-.06)$ and age of youngest (or only) child ( $\mathrm{t}=.46 ; \mathrm{p}=.65 ; \beta=.02$ ) were not significant predictors of workfamily conflict. However, age $(\underline{t}=-6.9 ; \mathrm{p} \leq .001 ; \beta=-.27)$, tenure $(\underline{\mathrm{t}}=4.3$; $\mathrm{p} \leq .001 ; \beta=.16)$, and number of dependents $(\mathrm{t}=3.3 ; \mathrm{p} \leq .001 ; \beta=.14)$ were significant predictors of overall work-family conflict.

In the present study, the examination of the effects of one's spouse/partner's sociodemographic variables on individuals' work-family conflict revealed new information which has not been previously examined. When employee work-family conflict was regressed on the set of spouse sociodemographic variables, the results revealed that spouse's age $(\mathrm{t}=-2.7 ; \mathrm{p} \leq .01 ; \beta=-.16)$ was a significant predictor of employees' work-family conflict. Also, when spouse work-family conflict was regressed on the set of employee sociodemographic variables, employees' age 
$(\mathrm{t}=-2.2 ; \mathrm{p} \leq .05 ; \beta=-.13)$ and employees' number of dependents $(\underline{t}=2.5 ; \mathrm{p} \leq .05 ;$

$\beta=.15$ ) was a significant predictors of spouses' work-family conflict.

Gender Differences in Work-Family Conflict. Student's paired $t$-test was used to test Hypothesis 6 to determine if females have significantly higher levels of work-family conflict than males. The means and standard deviations of work-family conflict for females and males were $2.7(\mathrm{SD}=.7)$ and $2.6(\mathrm{SD}=.6)$, respectively. The results of the Student's paired $t$-test revealed a significant difference between males and females on work-family conflict $(\underline{t}=121.6, \mathrm{p} \leq .001)$. This provides support for Hypothesis 6: that is, females experienced a higher level of work-family conflict than males.

Patterns of Work Involvement and Family Involvement by Couples. Hypothesis 7 (if the spouses/partners are symmetric in both work involvement and family involvement, their combined level of work-family conflict will be lower than the combined level of work-family conflict experienced by couples with other involvement patterns) was tested using a $1 \times 4$ ANOVA with four levels of work and family involvement for the couples. The combined level of work-family conflict was computed for each couple based on their mean level of work-family conflict. The participants were separated into two levels of work involvement (low $\leq 2.3$ and high $\geq 2.4$ ) and two levels of family involvement (low $\leq 3.7$ and high $\geq 3.8$ ) based on the midpoint of the present sample population. The relative frequencies of the couple's involvement patterns were determined based on the employee's level of work 
involvement and family involvement and his/her spouse/partner's level of work involvement and family involvement.

Four patterns of work involvement and family involvement were expected and did emerge: symmetric in both work and family, symmetric work-asymmetric family, asymmetric work-symmetric family, and asymmetric in both work and family. Couples were considered to be symmetric if they were both highly involved in work and family or if they both had low levels of work and family involvement; couples were considered to be asymmetric if they had different levels of work involvement and family involvement. The results of the $1 \times 4$ ANOVA with four levels of work and family involvement for the 436 couples revealed that there was a significant difference between the four levels of work and family involvement for the four groups of couples $(\underline{E}(47,388)=7.65 ; \mathrm{p} \leq .001)$. Further analyses were conducted using Student's paired $t$-test to compare the couples who were symmetric work-symmetric family to the other three groups of couples. Couples who were symmetric (both were highly involved in work and family or both had low levels of work and family involvement) in work and family involvement experienced the lowest levels of workfamily conflict. 


\section{Discussion}

\section{Tests of Hypotheses}

The present study examined the relationships between work involvement and work-family conflict and family involvement and work-family conflict in dual-career families. The following general results were revealed: work involvement accounted for a significant amount of variance in work-family conflict; family involvement accounted for a significant amount of variance in work-family conflict; the number of dependents accounted for a significant amount of variance in work-family conflict; work-family conflict was significantly higher for females than for males; and couples who were symmetric in their levels of work involvement and family involvement experienced lower levels of work-family conflict than couples who had asymmetric levels of work involvement and family involvement. The tests for the effects of one's spouse/partner's work involvement and one's spouse/partner's family involvement on individuals' work-family conflict was not significant. An examination of the moderating effects of number of dependents and age of youngest child on the relationships between work involvement and work-family conflict and family involvement and work-family conflict revealed that the proposed relationships were not significant.

Work involvement significantly predicted work-family conflict across study participants (H1). These results support previous research on the relationship between 
work involvement and work-family conflict (Frone \& Rice, 1987; Greenhaus et al., 1989). Perhaps, individuals with high levels of work involvement are more preoccupied with their work and hence, may devote a sufficient amount of energy to their work role (Greenhaus et al.). In the present study those individuals with high levels of work involvement may frequently think about their work when they are busy doing something else. Their involvement with their work may lead to greater demands and pressures from supervisors and co-workers, and a lessened ability to respond to demands and pressures from their spouse and children. In turn, their work involvement may interfere with the time they spend with their family or it may make it difficult to be the kind of partner/spouse or parent they would like to be.

Higgins, Duxbury, and Irving (1992) found that work conflict was the most significant predictor of work-family conflict. They suggest that the individuals' work environments may interfere with the amount of control they have over their level of work-family conflict. The present study supports the general model that work involvement is a strong predictor of work-family conflict for both men and women.

The finding that family involvement significantly predicted work-family conflict across study participants ( $\mathrm{H} 2)$ also provides support for previous research findings on the positive relationship between family involvement and work-family conflict (Greenhaus \& Beutell, 1985; Greenhaus \& Kopelman, 1981). In the present study, individuals were shown to be highly involved with their families and they may be spending a lot of their time on family and household activities. It seems that they would not be able to spend a lot of time on their own leisure activities. These people 
may go home from a long day at work, only to find themselves working the second shift at home (Hochschild, 1989). In her extensive interviews with 50 dual-career couples, Hochschild found that the strains associated with working the second shift often affects men, as well as, women. Although more often than not, the study found that the women tended to be the ones to be the primary caregiver and to work the second shift. When the men did share the responsibilities at home, they too felt strain (Hochschild). Hochschild observed that at times these parents felt fatigue or were sick due to their non-stop working. When men did not share the responsibilities for their children and their homes, they were indirectly affected by their wives working the second shift.

It is interesting, that both males and females reported higher levels of family involvement than work involvement. Also, males reported slightly higher levels of family involvement than their spouses. Perhaps, social desirability influenced the respondents to reply favorably to the family involvement items. They may have wanted to appear to be more highly involved with their families then they really were. Even though some of the respondents may have intentionally skewed their responses, it appears that they wanted their organization to be aware of their commitment to their families. This implies a shift away from the traditional views of work to a new focus on family.

The effects of both work involvement and family involvement together on individuals' levels of work-family conflict are not well documented. For example, the Greenhaus, et al. (1989) study on the sources of work-family conflict in 
dual-career couples did not include measures of family involvement or family stressors. Family involvement has been examined as a moderator of the relationship between work involvement and work-family conflict (Frone \& Rice, 1987). An examination of the relationship between family involvement and work-family conflict in dual-career couples is relatively new, since the majority of research prior to the present study has focused on the relationship between work involvement and work-family conflict. The present study demonstrates that family involvement is a significant component of the work-family conflict model, especially since so many individuals were highly involved with their families.

The most notable contribution of the present study was the examination of the effects of one's spouse's/partner's work involvement and one's spouse's/partner's family involvement on one's level of work-family conflict ( $\mathrm{H} 3$ and $\mathrm{H} 4)$. These relationships have not been previously examined in dual-career families. Hypothesis 3 and Hypothesis 4 are interesting aspects of the model of work-family conflict, because both partners are simultaneously participating in work and family activities. However, the tests of these hypotheses were not significant. That is, neither spouse work involvement nor spouse family involvement accounted for a significant amount of variance in employee work-family conflict; and neither employee work involvement nor employee family involvement account for a significant amount of variance in spouse work-family conflict. Individuals with higher levels of work involvement experienced greater levels of work-family conflict, but no evidence was found to suggest that an individual whose partner displays a high level of work involvement 
experienced intensified work and family pressures as demonstrated by their own level of work-family conflict. However, individuals with partners who were highly involved with their families did experience lower levels of work-family conflict as predicted. It appears that individuals' level of work-family conflict depends on their own levels of involvement with their work, and is also influenced by their spouses/partner's level of family involvement. These findings may have been different if these relationships had been examined between husbands and wives, men and women, and not "employees and spouses" as the present study did. Perhaps variables associated with job characteristics confounded these issues, and thus prevented directly comparing an individual to his/her spouse/partner at the couple's level (i.e., a naturally occurring dyad).

Although not specifically hypothesized, an examination of the effects of one's spouse/partner's sociodemographic variables on individuals' work-family conflict revealed new findings that have not emerged in previous research. When employee work-family conflict was regressed on the set of spouse sociodemographic variables, the results revealed that spouse's age was a significant predictor of employee's work-family conflict. Further, when spouse work-family conflict was regressed on the set of employee sociodemographic variables, employee's age and employee's number of dependents were significant predictors of spouse's work-family conflict.

One's spouse's age was a significant predictor of individual's work-family conflict. As previously discussed, an individual's age was a significant predictor of an individual's work-family conflict in the overall regression model. Also, one's 
spouse's age is very likely confounded with one's own age. There was a significant negative correlation between age and work-family conflict, as well as, between years married (or living together) and work-family conflict. These correlations suggest that as an individual gets older and as one's spouse gets older, work-family conflict for an individual decreases. Perhaps these individuals are better able to cope as they get older and are more experienced in dealing with major life events. The older couples may differ in cohorts from the younger people and may have never had high work-family conflict. Similarly, individuals' work-family conflict decreases the longer the couples are married. Couples may adapt to each other over time and thus reduce their levels of work-family conflict.

An important variable that was examined in the present study was the number of dependents (children and elderly) the couple reported living at home. The number of dependents accounted for a significant amount of variance in work-family conflict, as hypothesized (H5). The presence of children in the household has been shown to be related to increased levels of work-family conflict (Goff et al., 1990). Couples with young children usually spend more time and energy caring for them, which may correspond to higher levels of work-family conflict. Depending on the health of the relative, taking care of an elderly relative may place additional stressors on the individual from the increase in responsibilities and the amount of time and effort spent on caregiving. On the other hand, elderly relatives or older siblings may take care of the younger children or be responsible for household tasks. 
The finding that employees' number of dependents was a significant predictor of spouses' work-family conflict is interesting since the group of employees was $71.6 \%$ female and $28.4 \%$ male. This indicates that in the present study, the mostly male spouses' level of work-family conflict was affected by their partner's number of dependents to a greater degree than the mostly female employee group. The slight discrepancies in the number of dependents reported by the couples was presumably due to children by previous partners. This is ironic since the mostly male spouses had more children (i.e., the employees had an average of 0.9 dependents, while the spouses had an average of 1.2 dependents). The number of dependents does effect an individuals' level of work-family conflict. Although the spouse involvement interaction was not significant in the present study, perhaps better models of work-family conflict that include such variables can be developed. Other models examining the effects of one's spouse/partner's work involvement and family involvement, as well as one's sociodemographic variables on individual's work-family conflict, should continue to be explored.

This study demonstrated that the number of dependents living at home predicted work-family conflict (H5). Surprisingly, however, number of dependents did not moderate the relationship between work involvement and family involvement and work-family conflict (H8 and H9) nor did the age of couple's youngest (or only) child moderate these relationships ( $\mathrm{H} 10$ and $\mathrm{H} 11)$. The lack of significant findings may be related to the fact that there was a large number of survey respondents who reported having no children living at home. While over half (486) of the survey respondents 
reported having at least one child living at home, 378 of the survey respondents reported having no children living at home. Furthermore, there were only 15 survey respondents who reported having an elderly relative living at home.

The presence or absence of children and/or elderly in the household may be a better predictor of work-family conflict than number of dependents. However, hierarchical regression analyses were conducted examining the effect of number of children and number of elderly relatives living at home separately on work-family conflict, and not presence or absence of children and elderly. The significance of the predictor variable number of dependents was mainly due to the number of children living at home. There may be some individuals who provide a great deal of dependent care to elderly relatives even though they do not live at home. The amount of time spent with elderly relatives was assessed by only one item, and it referred to elderly relatives living at home. The present study did not examine the number of people giving care to elderly relatives who live on their own or with other relatives. Some individuals may spend a great deal of time with their elderly relatives on a daily or weekly basis doing various activities (grocery shopping, phone calls, visiting, helping with household tasks, personal grooming). An extensive study conducted on balancing work and caregiving by Neal, Chapman, Ingersoll-Dayton, \& Emlen (1993) found in a sample of 9,573 employed respondents, that $23 \%$ of these people were providing elder care.

Findings also demonstrated that the female study participants experienced higher levels of work-family conflict than the males (H6). These findings are consistent with 
earlier work by Pleck (1977) and Duxbury and Higgins (1991). Traditionally women have experienced more strain and tensions between their work and their family than men because women are the primary caregivers in the family (Hochschild, 1989). Maybe the gender differences in work-family conflict that were observed among these couples could partly be explained by female and male gender roles.

There is a lag in the re-distribution of roles, which Hochschild (1989) refers to as the stalled revolution, which may explain why these women would have higher levels of work-family conflict. For example, some males may not support their female partner's high level of work involvement, because it places greater demands on the male to participate in family activities. Employed women still assume the majority of the responsibility for child-care and household duties (Duxbury \& Higgins, 1991; Hochschild, 1989) and provide the majority of care to the elderly (Neal, et al, 1993). There may be negative sanctions associated with females who are highly involved in their work roles. That is, societal expectations regarding women and work may be incompatible with family expectations.

An examination of the work involvement and family involvement patterns of couples revealed that couples who were symmetric in their levels of work involvement and family involvement experienced lower levels of work-family conflict than couples who had asymmetric levels of work involvement and family involvement (H7). This finding is consistent with Yogev \& Brett (1985). Perhaps, couples who are similarly involved in both their work and family roles experience the lowest levels of workfamily conflict because they are able to devote time and energy to both their work and 
family roles, and thus achieve a balance between their work and family domains. Only recently Lobel (1991) suggested that dual-career families were managing to balance their work-family relationships quite effectively. If individuals have similar values and behaviors expressed in the two roles, this congruence implies a balance. That is, the individual who finds both work and family life equally satisfying experiences equivalent pressure to invest in both domains (Lobel). More individuals may be highly involved with their work, as well as, highly involved with their families.

New patterns in dual-career families that are characterized by both adults sharing responsibilities for children and the household (Rice, 1979) have been proposed. Past research over several years has failed to demonstrate an increase in males' family involvement (Duxbury \& Higgins, 1991). Similarly, Hochschild (1989) found that $18 \%$ of the men in her study shared approximately half the tasks with their spouses in the categories: housework, parenting, and management of domestic life. About $21 \%$ of the men in that study did a moderate amount of work (between 30 and $45 \%$ ); and $61 \%$ did little (between $30 \%$ and none) (Hochschild, 1989). However, the present study presents new evidence that shows that both members of dual-career couples are highly involved in their families, even more than they are involved in their work. This finding is based on self-report measures, and the respondents may have skewed their responses because of the social desirability associated with high family involvement. How women and men balance the competing demands between work and family obligations is of considerable interest to general models of work-family 
conflict. DiBenedetto and Tittle (1990) reported from census data that some of the methods that married women are currently employing to attempt to balance their work and family domains include delaying childbearing, working part-time or part of the year or entering jobs with flexible hours, and hiring household help or making child-care arrangements. In the present study, there were a significant number of individuals who did not have children. Therefore, deciding not to have children may be another way that women are attempting to balance their work and family lifes.

Women who were successful at managing multiple roles of spouse, parent, and worker experienced the least guilt when it came to delegating duties at work or at home (Epstein, 1987). Perhaps these women are married to men who share a great deal of the child-care and household responsibilities, and sharing these tasks takes a lot of pressure off of these women, thereby reducing their work-family conflict. Regardless of how women and men are managing their work and family domains, it is clear from the present study that both women and men are highly involved with their families. The modification of family roles, together with the expansion of support services (e.g., child care, housekeeping, and maintenance workers), are seen as altering a major structural barrier to women's achievement in the work force. Hochschild (1989) stated that major social and political changes are needed to improve the stalled revolution. When both partners share the responsibilities at home and for their children, then they may reduce the amount of work-family conflict between them. Hochschild (1989) reported less strain among dual-career couples with children when husbands and wives were both working the second shift at home. It is 
evident that, a significant number of dual-career families are able to satisfactorily balance the domains of work and family. This is demonstrated by the relatively low levels of work-family conflict that were found in the present study. Caution should be used when examining these low levels of work-family conflict because respondents may have avoided using the extreme endpoints on the work-family scales, and therefore, work-family conflict may still be present.

Yet if work-family conflict is indeed lower than previously reported, and this trend continues, then this knowledge may lend support to the positive effects of self-complexity (Linville, 1987). The self-complexity model views the self as multi-faceted, represented by multiple self-aspects. That is, an individual may think of himself or herself as a husband or wife, father or mother, worker, athlete, and so forth. Each role or activity may contain its own features associated with that self-aspect. Linville's model states that there is greater self-complexity if there are more self-aspects and greater distinctions among them. Therefore, people who have lower self-complexity may be affected more dramatically by stressful life events, than individuals who have higher self-complexity (Linville). Individuals with higher self-complexity may not be affected by a stressful life event, because it only affects one self-aspect and may not spread to other self-aspects.

It has been well documented that their are benefits associated with multiple roles on individual well-being (Coleman, Antonucci \& Adelmann, 1987). Individuals with multiple roles and positive self-aspects may have less stress and better health than individuals with fewer or negative self-aspects. Linville states that having greater 
self-complexity moderates the adverse affects of stressful events on physical and mental health outcomes (1987). Maybe, simply put, couples who are more involved with their work and families, and have multiple roles, enjoy their involvement in both domains and do not feel constrains between them.

\section{Limitations of the Study}

Criticisms of the present study include: 1) lack of objective measures of work involvement and family involvement and problems associated with using self-reports; 2) limited generalizations to dual-career families who are Caucasian and over 40 years old; 3) the comparison of employees to spouses instead of husbands to wives (or men to women) for the spouse involvement interactions; and 4) the need for additional statistical tests using path analysis to more closely examine the influence of social demographics and spouse involvement interactions. These criticisms will be discussed in turn.

\section{Lack of Objective Measures of Work Involvement and Family Involvement and} Problems Associated with Using Self-Reports. Work involvement and family involvement are conceptualized as having both subjective and objective components. However, in the present study, the objective items were not included as part of the analyses because it was difficult to precisely measure the number of hours spent in work and family/personal activities across individuals. For example, the survey used in the present study asked "about how much time do you spend on various activities daily", and the response blank indicated "hours". The survey did not account for all 24 hours of the day, because it did not include time spent eating and sleeping. It was 
not possible to compare these measures across individuals because the scales were not standardized. Also, the objective items did not differentiate between time spent on various activities on days worked and days not worked. This information would indeed be helpful. We may ask how much time was spent at work or at home physically, but we can not measure how much time was spent thinking about work or family. For example, the number of hours spent on work activities does not include the amount of time spent getting ready for work or time spent traveling to work, which may be time taken away from children and spouses.

The objective work involvement items included number of hours worked per week and number of hours spent on work activities. There were more objective family involvement items than the work-related items, because family time was divided into various activities (e.g., child-care, elderly-care, and family/personal activities). Therefore, the objective work involvement and family involvement items were excluded from the data analyses, because they could not be directly compared. Reliable and valid objective measures of work involvement and family involvement are needed.

There are also problems inherent with using measures that rely solely on self-reports. Social desirability plays a significant role in influencing subjects responses while they are self-reporting. In the present study, the respondents may have intentionally skewed their responses to make it appear that they were highly involved with their families. Perhaps some of the respondents did bias their answers. 
They may have intentionally wanted their organization to be aware of their commitment to their families.

Limited Generalizations to Dual-Career Families. Although the present study revealed a great deal of information on dual-career families, caution should be taken when generalizing the results to other populations. The couples who participated in the study were all male/female couples whose average age was 42 , and $91 \%$ of the couples were Caucasian. This raises some speculation about the characteristics of those individuals who did not respond to the survey. The present study had a $50 \%$ response rate. Those individuals who did not respond may have been experiencing too many demands and pressures at work or at home and could not take the time to fill-out the survey. Hochschild found that dual-career couples who were experiencing a lot of strain from their work-family lifes, were the very people who could not take the time to be interviewed (1989). In the present study, the non-respondents may have been similar to the respondents in demographics and may have been similarly involved with their work and their families. The non-respondents may have been from different ethnic backgrounds or they may have led different lifestyles than the respondents. For example, perhaps couples who were living together and were not married did not feel that they should respond, even though it was stated in the cover letter that they did not have to be married, they only had to be in a relationship and living together for three years. There were presumably a number of couples who did not fill-out the questionnaire, because they had been together less than three years. Also, there were fewer than 20 couples who completed the survey who were the same 
sex. Although only male and female couples were used in the present study, couples who were gay or lesbian may not have wanted to participate in the study due to personal reasons or fear of stigma.

Furthermore, all of the employees, one-half of the sample, were employed by a bank organization. Since a stratified random sampling procedure was used to represent the bank organization in the Northwest United States, the employees may share common work experiences and have similar feelings about their work, and thus experience similar strains associated with their work. Generalizations to other groups of employees in various careers may be somewhat limited. In the present study, the items used for job classifications were relative to the bank business for employees, while the spouse job classifications were more broadly defined. Therefore, employees' and spouses' job classifications could not be directly compared. This may have been another factor influencing the results of the study since job classification was not controlled for in the multiple regression analyses.

The Comparison of Employees to Spouses Instead of Husbands to Wives. Comparing employees to spouses instead of comparing males to females for the influence of one's spouse's work and family involvement on individual's level of work-family conflict was another limitation of the study. The true underlying relationships between the partners and their influence on one another's work-family conflict was confounded with the variables employee and spouse. This may have prevented analyses at the level of the couple, who are indeed a male and a female and/or a husband and a wife (i.e., a naturally occurring dyad), and not just an 
"employee" and a "spouse". Also, job characteristics may have been a confounding variable. By intentionally trying to avoid focusing on gender issues in this study, these interactions were not significant when comparing an employee to his/her spouse.

The Need for Path Analysis. Since it was not the intent of the present study to conduct path analysis, a full model to explain the role of social demographics, work and family involvement, and the effects of one's partner's work and family involvement on an individual's level of work-family conflict was not developed. Further statistical tests should be conducted on the model of work-family conflict to determine if the interaction of one's work involvement with one's spouse/partner's work involvement, and the interaction of one's family involvement with one's spouse/partner's family involvement predict individual's work-family conflict. Path analysis would provide useful information on the direction of these variables and their effects upon one another on those variables which best predict work-family conflict. Which variables should be included in the model of work-family conflict and what are their proposed relationships? Should the model include work and family expectations, spouse involvement with work and family, or involvement with one's own spouse? It would be beneficial to both employees and companies to cash in on the knowledge that stems from understanding both the benefits and strains that arise in the work and family domains and their underlying relationships.

\section{Implications for Future Research}

Future research should further examine the relationship between work involvement and family involvement and work-family conflict in a variety of career 
patterns for couples (single- and dual-career). How do these couples differ in their levels of work-family conflict, or do they have similar levels of work-family conflict depending whether they are a single- or dual-career couple? Also, how do job classifications and specific work characteristics (e.g., number of hours worked) influence work-family conflict?

Another area of research that could be expanded is the addition and clarification of various sociodemographic variables. For example, researchers should pay particularly closer attention to the effects of one's age on his or her level of workfamily conflict. Since age was a significant predictor of work-family conflict and age correlated negatively with work-family conflict, researchers should further investigate this relationship. Studies on work-family conflict in conjunction with studying across life stages using a longitudinal design may help explain why younger individuals experience more perceived conflict than individuals who are middle age and older. Such a study may discover that older persons report lower levels of work-family conflict than younger adults do, because they do not perceive as much strain from their work and family lifes. It would be interesting to examine both age and gender differences in longitudinal data to determine how work-family conflict is negatively affected by age, and to a lesser extent by gender.

Another variable that could be further explored is the level of education of an individual and their spouse, and its influence on one's work involvement, family involvement and work-family conflict. It would be interesting to know whether one's level of education positively affects work-family conflict. Are individuals with high 
degrees more involved with their work than individuals without degrees, and do they experience higher levels of work-family conflict? Would an individual with only an elementary degree experience more work-family conflict than an individual with a high-school diploma or less?

Additional studies are needed which include more measures which are common to both partners in dual-career families. How much time do couples spend with each other, how involved are they in each other's lives? Future research should focus on the interaction between an individual's work involvement with one's spouse/partner's work involvement, and the interaction between an individual's family involvement with one's spouse/partner's family involvement, to examine their effects on individuals' work-family conflict.

Another variable that couples share is the number of dependents among them living in their house. Perhaps, the presence or absence of children and/or elderly in the home may account for more variance in work-family conflict than the variance that number of dependents accounted for in the present study. The presence or absence of children and/or elderly dependents may moderate the relationships between work involvement and work-family conflict and family involvement and work-family conflict. It could be that older siblings and elderly relatives aid in caring for the younger children and they may perform household chores. The amount of care that an individual provides to their family (spouse, children, and elderly) should be included in the model of work-family conflict. The amount of elder care that is being provided by employed individuals is more prevalent than previously thought, and this 
has an impact on U.S. companies (Neal, et al., 1993). Caring for elderly relatives and caring for one's children are vastly different activities. Individuals may experience different feelings and emotions, and different demands and pressures from their children than they experience from their elderly relatives. The amount of care that they provide may, in turn, affect their level of work-family conflict.

Additional research should examine the positive effects associated with multiple roles (worker, spouse, parent) employing the self-complexity theory (Linville, 1987). Self-complexity acts like a buffer to stress-related events and may influence health related outcomes, because having more self-aspects is associated with being able to cope better with stressful life events. Perhaps the fact that the dual-career families in the present study did not have significantly high levels of work-family conflict, it implies that the simultaneous participation in both work and family may have positive benefits to both men and women alike.

The relationship between work involvement and family involvement and work-family conflict is a fundamental component of the interface between work and family. Companies need to understand and anticipate adjustments needed in work roles, family roles, and organizational structures to support workers' abilities to adapt to the changing workplace constructively. As Hochschild suggests, the stalled revolution may need social and political changes to happen (1989). Those companies that make adjustments to their policies and allow workers more flexibility over their work schedules will adapt to what may be a transitional shift away from work and toward the family. 


\section{References}

Amatea, E. S., Cross, E. G., Clark, J. E., \& Bobby, C. L. (1986). Assessing the work and family role expectations of career-oriented men and women: The life role salience scales. Joumal of Marriage and Family, 48, 831-838.

Burke, R. J. (1988). Some antecedents and consequences of work-family conflict. Journal of Social Behavior and Personality, 3(4), 287-302.

Cohen, J., \& Cohen, P. (1983). Applied multiple regression/correlation analysis for the behavioral sciences. Hillsdale: Lawrence Erlbaum Associates, Inc.

Coleman, L. M., Antonucci, T. C., \& Adelmann, P. K. (1987). Role Involvement, gender, and well-being. In F. J. Crosby (Ed.), Spouse,Parent, Worker: On gender and multiple roles. (Chap. 10, 138-153). New Haven: Yale University Press.

Cooke, R. A., \& Rousseau, D. M. (1984). Stress and strain from family roles and work-role expectations. Journal of Applied Psychology, 69, 252-260.

DiBenedetto, B., \& Tittle, C. K. (1990). Gender and adult roles: Role commitment of women and men in a job-family trade-off context. Journal of Counseling Psychology, 37(1), 41-48.

Duxbury, L. E., \& Higgins, C. A. (1991). Gender differences in work-family conflict. Journal of Applied Psychology, 76, 60-74. 
Epstein, C. F. (1987). Multiple demands and multiple roles: The conditions of successful management. In F. J. Crosby (Ed.), Spouse, Parent, Worker: On gender and multiple roles (Chap. 3, 23-35). New Haven: Yale University Press.

Frone, M. R., \& Rice, R. W., (1987). Work-family conflict: The effect of job and family involvement. Journal of Occupational Behavior, 8, 45-53.

Frone, M. R., Russell, M., \& Cooper, M. L. (1992). Antecedents and outcomes of work-family conflict: Testing a model of the work-family interface. Journal of Applied Psychology, 77(1), 65-78.

Goff, S. J., \& Mount, M. K. (1992, May). Job involvement as a moderator of the relation between work role pressures and work-family conflict. Symposium conducted at the meeting of the Society for Industrial and Organizational Psychology, Montreal, Quebec.

Goff, S. J., Mount, M. K., \& Jamison, R. L. (1990). Employer supported child care, work/family conflict, and absenteeism: A field study. Personnel Psychology, 43, 793-809.

Greenhaus, J. H., \& Beutell, N. J. (1985). Sources of conflict between work and family roles. Academy of Management Review, 10, 76-88.

Greenhaus, J. H., \& Kopelman, R. E. (1981). Conflict between work and nonwork roles: Implications for the career planning process. Human Resource Planning, 4(1), 1-10. 
Greenhaus, J. H., Parasuraman, S., Skromme Granrose, C., Rabinowitz, S., \& Beutell, N. J. (1989). Sources of work-family conflict among two-career couples. Journal of Vocational Behavior, 34, 133-153.

Gupta, N., \& Jenkins, G. D. (1985). Dual-career couples: Stress, stressors, strain, and strategies. In T. A. Beehr \& R. S. Bhagat (Eds.), Human stress and cognition in organizations: An integrated perspective (pp. 141-175). New York: Wiley-Interscience.

Hall, D. T., \& Richter, J. (1988). Balancing work life and home life: What can organizations do to help? Academy of Management Executive, 1, 213-223.

Higgins, C. H., Duxbury, L. E., \& Irving, R. H. (1992). Work-family conflict in the dual-career family. Organizational Behavior and Human Decision Processes, 51, 51-75.

Hochschild, A. (1989). The second shift. New York: Avon Books.

Kahana, E., \& Young, R. (1990). Clarifying the caregiving paradigm. In D.E. Biegel \& A. Blum (Eds.), Aging and caregiving: Theory, research, and policy. Newbury Park, CA: Sage.

Kahn, R. L., Wolfe, D. M., Quinn, R., Snoek, J. D., \& Rosenthal, R. A. (1964). Organizational Stress. New York: Wiley.

Kopelman, R., Greenhaus, J. H., \& Connolly, T. F. (1983). A model of work, family, and interrole conflict: A construct validation study. Organizational Behavior and Human Performance, 32, 198-215. 
Lamb, M. E., Chase-Lansdale, L., \& Owen, M. T. (1979). The changing American family and its implications for infant social development: The sample case of maternal employment. In M. Lewis and L. A. Rosenblum (Eds.), The Child and Its Family. New York: Plenum Press.

Leap, T. L., \& Crino, M. D. (1989). Labor force issues: Composition, trends, and equal employment opportunity. In T. L. Leap and M. D. Crino (Eds.), Personnel/Human Resource Management, (Chap. 3, pp. 28-66). New York: Macmillan Publishing Company.

Linville, P. W. (1987). Self-complexity as a cognitive buffer against stress-related illness and depression. Journal of Personality and Social Psychology $\underline{52}(4), 663-676$.

Lobel, S. A. (1991). Allocation of investment in work and family roles: Alternative theories and implications for research. Academy of Management Review, 16. $507-521$.

Lodahl, T. M., \& Kejner, N. (1965). The definition and measurement of job involvement. Journal of Applied Psychology, 49, 24-33.

Neal, M. B., Chapman, N. J., Ingersoll-Dayton, B., \& Emlen, A. C. (1993). Balancing work and caregiving for children, adults, and elders. Newbury Park: Sage Publications, Inc.

Offerman, L., \& Gowing, M. (1990). Organizations of the future: Changes and challenges. American Psychologist, 45, 95-108. 
Pleck, J. H. (1977). The work-family role system. Social Problems, 24. 417-425.

Quinn, R., \& Staines, G. (1979). The 1977 quality of employment survey. Ann Arbor: University of Michigan, Survey Research Center.

Rapoport, R., \& Rapoport, R. N. (1971). Dual-career families. London: Penguin.

Rapoport, R., \& Rapoport, R. N. (1976). Dual-career families re-examined. New York: Harper-Row.

Repetti, R. L., Matthews, K. A., \& Waldron, I. (1989). Effects of paid employment on women's mental and physical health. American Psychologist, 44(11), 1389-1413.

Rice, D. G. (1979). Dual-career marriage. New York: The Free Press.

Ridley, C. A. (1973). Exploring the impact of work satisfaction and involvement on marital interaction when both partners are employed. Journal of Marriage and the Family, 35, 229-237.

Sekaran, U. (1986). Dual-career families. San Francisco: Jossey-Bass.

Staines, G. L., Pottick, K. J., \& Fudge, D. A. (1986). Wives' employment and husbands' attitudes toward work and life. Journal of Applied Psychology, 71, 118128.

U.S. Department of Labor. (1987). Over half of mothers with children one year old or under in labor force in March 1987. Bureau of Labor. Washington, DC: Author. 
Yogev, S., \& Brett, J. (1985). Patterns of work and family involvement among single- and dual-earner couples. Journal of Applied Psychology, 70, 754-768.

Zarit, S. H., Orr, N. K., \& Zarit, J. M. (1985). The hidden victims of Alzheimer's disease: Families under stress. New York: New York University Press.

Zedeck, S., \& Mosier, K. (1990). Work in the family and employing organization. American Psychologist, 45, 240-251. 
Table I

Number of Survey Respondents, Means and Standard Deviations for Family Characteristics Computed by Couples

Number of Employee Survey Respondents (436)

Number of Spouse/Partner Survey Respondents (436)

Number of Female Employees (312)

Number of Male Spouse/Partners (312)

Number of Male Employees (124)

Number of Female Spouse/Partners (124)

Age of Employee $(\underline{\mathrm{M}}=41.3, \underline{\mathrm{SD}}=9.9)$

Age of Spouse/Partner $(\underline{\mathrm{M}}=42.8, \underline{\mathrm{SD}}=10.5)$

Combined

Range

Study Variables

$\underline{\mathbf{M}}$

$\underline{\text { SD }}$

Min $\quad$ Max

Age

42.0

10.2

22

82

Years Married (If Married) or Living Together

15.8

10.3

3

48

Number of Children Living at Home

$1.0 \quad 3.2$

0

10

Note. $\underline{N}=872$ Survey Respondents; 436 Couples (436 Females: 436 Males).

$\underline{\mathrm{M}}=$ Mean; $\underline{\mathrm{SD}}=$ Standard Deviation; Min $=$ Minimum; Max $=$ Maximum. 
Table I

Number of Survey Respondents, Means and Standard Deviations for Family Characteristics Computed by Couples (continued)

\begin{tabular}{|c|c|c|c|c|}
\hline \multirow[b]{2}{*}{ Study Variables } & \multicolumn{2}{|c|}{ Combined } & \multicolumn{2}{|c|}{ Range } \\
\hline & $\underline{\mathbf{M}}$ & $\underline{\mathrm{SD}}$ & Min & Max \\
\hline Age of Youngest (or Only) Child & 0.3 & 0.5 & 0 & 26 \\
\hline Age of Oldest Child & 11.6 & 5.4 & 0 & 26 \\
\hline Number of Elderly Relatives Living at Home & $<1$ & 0.3 & 0 & 2 \\
\hline
\end{tabular}

Note. $\underline{\mathbf{N}}=872$ Survey Respondents; 436 Couples (436 Females: 436 Males).

$\underline{M}=$ Mean; $\underline{\mathrm{S}}=$ = Standard Deviation; Min = Minimum; Max $=$ Maximum. 
Table II

Distribution of Family Characteristics for Survey Respondents

\begin{tabular}{|c|c|c|c|c|}
\hline & Demographic Variables & Employee & Spouse/Partner & Combined \\
\hline \multirow[t]{4}{*}{ Age: } & $22-33$ & 115 & 93 & 208 \\
\hline & $34-45$ & 172 & 182 & 354 \\
\hline & $46-57$ & 119 & 119 & 238 \\
\hline & $58-82$ & 29 & 39 & 68 \\
\hline \multicolumn{2}{|c|}{ Ethnic: African American } & 5 & 5 & 10 \\
\hline & American Indian & 1 & 3 & 4 \\
\hline & Asian & 11 & 6 & 17 \\
\hline & Caucasian & 395 & 409 & 804 \\
\hline & Hispanic & 9 & 7 & 16 \\
\hline & Other & 12 & 6 & 18 \\
\hline
\end{tabular}

Note. $\underline{N}=872$ Survey Respondents; 436 Couples. 
Table II

Distribution of Family Characteristics for Survey Respondents

(continued)

\begin{tabular}{cc}
\hline \begin{tabular}{l} 
Demographic Variables \\
\cline { 2 - 2 } Marital Status:
\end{tabular} & \multicolumn{1}{c}{ Combined } \\
Married and Living with Spouse & 860 \\
Single and Living with Partner & 12 \\
Years Married or Living with Spouse/Partner: & 183 \\
$3-6$ & 241 \\
$7-12$ & 242 \\
$13-23$ & 157 \\
$24-35$ & 46 \\
$36-48$ & \\
\hline
\end{tabular}

Note. $\underline{\mathbf{N}}=872$ Survey Respondents; 436 Couples). 
Table II

Distribution of Family Characteristics for Survey Respondents

(continued)

Demographic Variables

Combined

\section{Number of Children Living at Home:}

0

378

1

229

2

198

$>3$

59

Number of Individuals with Children 6 Years Old or Younger:

Number of Individuals with Children Older than 12 Years:

Number of Elderly Relatives Living at Home:

0

834

$1-2$

15

Note. $\underline{N}=872$ Survey Respondents; 436 Couples). 
Table III

Means and Standard Deviations for Work Characteristics by Couples

\begin{tabular}{|c|c|c|c|c|c|c|c|c|}
\hline \multirow[b]{2}{*}{ Study Variables } & \multicolumn{2}{|c|}{ Employee } & \multicolumn{2}{|c|}{ Spouse/Partner } & \multicolumn{2}{|c|}{ Combined } & \multicolumn{2}{|c|}{ Range } \\
\hline & $\underline{\mathbf{M}}$ & $\underline{\mathrm{SD}}$ & $\underline{M}$ & $\underline{\mathrm{SD}}$ & $\underline{\mathbf{M}}$ & $\underline{\mathrm{SD}}$ & Min & $\operatorname{Max}$ \\
\hline Years Worked (Tenure) & 11.0 & 8.5 & 8.5 & 7.8 & 9.8 & 8.3 & 0 & 42 \\
\hline Actual Hours Worked/Week & 43.2 & 8.4 & 44.1 & 10.9 & 41.3 & 9.7 & 20 & 90 \\
\hline Hours Prefer to Work/Week & 37.5 & 7.2 & 36.0 & 11.1 & 37.0 & 9.3 & 0 & 50 \\
\hline Overtime Hours/Week & 2.6 & 6.7 & 5.8 & 7.9 & 4.8 & 7.7 & 0 & 50 \\
\hline \multicolumn{9}{|c|}{ Due to Family/Personal-Related Issues (In Past Four Weeks): } \\
\hline Times Late & 0.6 & 2.3 & 0.4 & 2.3 & 0.5 & 2.3 & 0 & 28 \\
\hline Times Interrupted & 3.3 & 5.5 & 2.5 & 6.2 & 2.9 & 5.8 & 0 & 80 \\
\hline Days Missed & 0.4 & 1.3 & 0.4 & 1.3 & 0.4 & 1.3 & 0 & 16 \\
\hline
\end{tabular}

Note. $\quad \underline{N}=872$ Survey Respondents; 436 Couples.

$\underline{\mathrm{M}}=$ Mean; $\underline{\mathrm{SD}}=$ Standard Deviation; Min = Minimum; Max $=$ Maximum. 
Table IV

Distribution of Work Characteristics for Survey Respondents

Demographic Variables Employee Spouse/Partner $\quad$ Combined

Years Worked (Tenure):

$<1$ Year to 10

$11-26$

$27-42$

Schedule:

Standard

Part-time

Flexible Hours

Job-Sharing

Compressed and Other
169

24

306

67

39

6

14
255

118

11

228

35

63

4

85
493

287

35

534

102

102

10

99

Note. $\quad \underline{N}=872$ Survey Respondents; 436 Couples. 
Table IV

Distribution of Work Characteristics for Survey Respondents

(continued)

Demographic Variables Employee $\quad$ Spouse/Partner $\quad$ Combined

Actual Hours Worked Per Week:

$\begin{array}{rrrr}20-32 & 44 & 45 & 89 \\ 33-45 & 259 & 204 & 463 \\ 46-84 & 125 & 129 & 254\end{array}$

Flexibility in Work Schedule:

A lot

84

124

208

Some

260

201

521

Hardly Any to None

92

73

165

Note. $\quad \underline{N}=872$ Survey Respondents; 436 Couples. 
Table V

Means and Standard Deviations for Work-Family Scales by Couples

Cronbach's

\begin{tabular}{|c|c|c|c|c|c|c|c|}
\hline \multirow[b]{2}{*}{ Study Variables ${ }^{a}$} & \multicolumn{2}{|c|}{ Employee } & \multicolumn{2}{|c|}{ Spouse/Partner } & \multicolumn{2}{|c|}{ Combined } & \multirow[t]{2}{*}{ Alpha } \\
\hline & $\underline{\mathbf{M}}$ & $\underline{S D}$ & $\underline{\mathbf{M}}$ & $\underline{S D}$ & $\underline{\mathbf{M}}$ & $\underline{S D}$ & \\
\hline Work Involvement & 2.5 & 0.7 & 2.4 & 0.7 & 2.4 & 0.7 & 0.86 \\
\hline Family Involvement & 3.6 & 0.7 & 3.9 & 0.6 & 3.7 & 0.7 & 0.87 \\
\hline Work-Family Conflict & 3.3 & 0.9 & 2.6 & 0.6 & 2.6 & 0.6 & 0.85 \\
\hline
\end{tabular}

Note. $\quad \underline{N}=872$ Survey Respondents; 436 Couples.

$\underline{\mathrm{M}}=$ Mean; $\underline{\mathrm{SD}}=$ Standard Deviation; Min $=$ Minimum; Max $=$ Maximum.

a = Means Range from 1 (Low Involvement/Conflict) to 5 (High Involvement/Conflict). 
Table VII

Results of Multiple Regression Analysis of Work-Family Conflict on Study Variables

\begin{tabular}{|c|c|c|}
\hline \multirow[b]{2}{*}{ Independent Variable } & \multicolumn{2}{|c|}{ Survey Respondents $(N=872)$} \\
\hline & $\Delta \mathrm{R}^{2}$ & $E$ for $\Delta R^{2}$ \\
\hline Demographics & .107 & $18.98 * * *$ \\
\hline \multicolumn{3}{|l|}{ Age } \\
\hline \multicolumn{3}{|l|}{ Sex } \\
\hline \multicolumn{3}{|l|}{ Years Worked (Tenure) } \\
\hline \multicolumn{3}{|l|}{ Number of Dependents ${ }^{a}$} \\
\hline \multicolumn{3}{|l|}{ Age of Youngest (or only) Child } \\
\hline Work Involvement & .040 & $36.95^{* * *}$ \\
\hline Family Involvement & .006 & $5.62 *$ \\
\hline Work Involvement X Dependents ${ }^{a}$ & .040 & 0.42 \\
\hline Family Involvement $\mathrm{X}$ Dependents $\mathrm{s}^{\mathrm{a}}$ & .007 & 0.77 \\
\hline Work Involvement X Age Youngest Child & .040 & 0.65 \\
\hline Family Involvement $X$ Age Youngest Child & .006 & 0.03 \\
\hline
\end{tabular}

Note. $\mathrm{F}:{ }^{*} \mathrm{p} \leq .05 ;{ }^{* *} \mathrm{p} \leq .01 ; * * * \mathrm{p} \leq .001$.

$2=$ Children and Elderly Living at Home. 
Table VIII

Results of Multiple Regression Analysis of Employee Work-Family Conflict on Spouse Study Variables

Couples $(N=436)$

Independent Variable $\Delta \mathrm{R}^{2}$ E for $\Delta R^{2}$

Spouse Demographics

.036

$2.77 *$

Age

Sex

Years Worked (Tenure)

Number of Dependents

Age of Youngest (or Only) Child

Spouse Work Involvement

.003

1.16

Spouse Family Involvement

.009

Spouse Work Involvement X Dependents ${ }^{\mathrm{a}}$

.003

0.11

Spouse Family Involvement X Dependents ${ }^{\mathrm{a}}$

.010

0.36

Spouse Work Involvement X Age Youngest Child

.005

0.78

Spouse Family Involvement X Age Youngest Child

.009

0.16

Note. $\mathrm{E}:{ }^{*} \mathrm{p} \leq .05$.

$s=$ Children and Elderly Living at Home. 
Table IX

Results of Multiple Regression Analysis of Spouse/Partner Work-Family Conflict on Employee Study Variables

Couples $(N=436)$

Independent Variable

$\Delta \mathrm{R}^{2}$

E for $\Delta R^{2}$

Employee Demographics

.051

$4.06 * *$

Age

Sex

Years Worked (Tenure)

Number of Dependents ${ }^{a}$

Age of Youngest (or Only) Child

Employee Work Involvement

.004

1.61

Employee Family Involvement

.000

0.00

Employee Work Involvement X Dependents ${ }^{a}$

.004

0.06

Employee Family Involvement X Dependents ${ }^{a}$

.001

0.12

Employee Work Involvement X Age Youngest Child

.004

0.09

Employee Family Involvement X Age Youngest Child

.001

0.16

Note. $\mathrm{E}:{ }^{*} \mathrm{p} \leq .05 ;{ }^{* *} \underline{\mathrm{P}} \leq .01$.

$\stackrel{a}{=}$ Children and Elderly Living at Home. 
Appendix

Cover Letters and Survey Questionnaire 


\section{EMPLOYEE SURVEY}

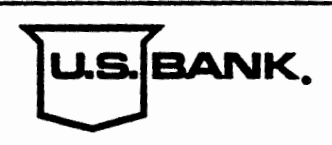

Dear U.S. Bancorp Employee,

You have been randomly selected to participate in a survey conducted jointly by U.S. Bancorp and Portland State University (PSU) assessing the needs for alternative work schedules at U.S. Bancorp.

The purpose of the survey is twofold. U.S. Bancorp is interested in assessing the benefits of alternative work schedules. PSU is conducting research on some of the factors that contribute to conflicts that arise between work and non-work aspects of our lives. Your voluntary participation is important to this project and we encourage you and your spouse/partner, if applicable, to complete the enclosed surveys. There is no intent or desire to identify any individual completing the survey. Your responses will be anonymous in that your name or specific work group will not appear anywhere on the survey form. The numbers you see on the surveys are included for the sole purpose of being able to match you and your spouse/partner's survey when they are returned. No one outside of the PSU research team will see the completed questionnaires. The PSU researchers will group the individual data (making it anonymous) and report the overall results to U.S. Bancorp's Human Resources Group.

Supervisors and managers have been notified that a random sample of employees will be completing surveys between the dates of September 9-18 and that employees are to be allowed company time to complete their survey in private and away from their workstations. The survey should take no longer than 30 minutes to complete. Please let your supervisor know if you need any help in making arrangements to complete your survey. Please fill out the questionnaire marked $E$ in the upper right hand corner and give the questionnaire marked S/P to your spouse/partner, if applicable. If a spouse/partner is also completing a survey please do not discuss individual responses prior to completion. After the survey is completed, please mail to Dr Hammer at Portland State University in the enclosed self-addressed envelope as soon as possible.

If you have any questions about the survey feel free to contact Doreen Grove in Human Resources at (503) 275-6147, Dr Leslie Hammer or Tenora Grigsby at Portland State University at (503) 725-3878. We appreciate your time in helping us with this research project. Your input is important in understanding how people feel about AWS at U.S. Bancorp.

Sincerely,

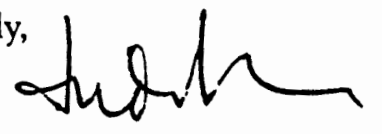

Judy Rice, Executive Vice President Human Resources Group U.S. Bancorp

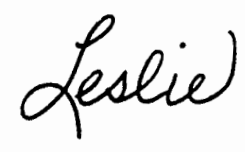

Leslie Hammer, Ph.D. Department of Psychology Portland State University 


\section{SPOUSE/PARTNER SURVEY}

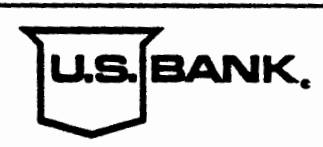

Dear Survey Participant,

Your spouse or partner has been randomly selected to participate in a survey conducted jointly by U.S. Bancorp and Portland State University (PSU). We are collecting information on alternative work schedules at U.S. Bancorp as well as some of the factors that contribute to conflicts that arise between work and nonwork aspects of our lives. The portion of the survey for spouses or partners will provide PSU with additional information on work and non-work demands.

Your voluntary participation is important to this project and we encourage you, as a spouse/partner of an employee of U.S. Bancorp to complete the enclosed survey. There is no intent or desire to identify any individual completing the survey. Your responses will be anonymous in that your name will not appear anywhere on the survey form. The number you see on the survey is included for the sole purpose of being able to match you and your spouse/partner's survey when they are returned. No one outside of the PSU research team will see the completed questionnaires. The PSU researchers will group the individual data (making it anonymous) and the overall results of this spouse/partner survey will only be used by the PSU research team.

Please complete the survey between the dates of September 9-18, 1992 at a time that is convenient for you. The survey should take no longer than 30 minutes to complete. Please fill out the questionnaire marked $S / P$ in the upper right hand corner. Please do not discuss individual responses of the survey with your spouse/partner prior to completion. After the survey is completed, please mail to Dr. Hammer at Portland State University in the enclosed self-addressed envelope as soon as possible.

If you have any questions about the survey feel free to contact either Dr. Leslie Hammer or Tenora Grigsby at Portland State University at (503) 725-3878. We appreciate your time in helping us with this research project. Your input is important in understanding how to better balance work and family demands.

Sincerely,

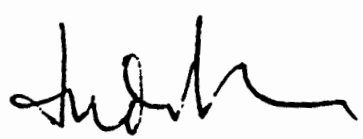

Judy Rice, Executive Vice President Human Resources Group U.S. Bancorp

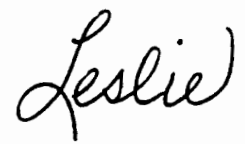

Leslie Hammer, Ph.D. Department of Psychology Portland State University 
I. Sociodemographic Information

Please mark an $\mathrm{X}$ in the box that represents the response that is most appropriate.

1. Age: 1.[ ] less than $20 \mathrm{yrs}$
2.[ ] 20-30 yrs
3.[ ] 31-40 yrs
4.[ ] $41-50 \mathrm{yrs}$
5.[ ] 51-60 yrs
6.[ ] 61 yrs and above

\section{Sex: 1.[ ]F 2.[ ] $\mathrm{M}$}

3. Ethnic background:
1.[ ] African American 4.[ ]Hispanic
2.[ ] Asian
5.[ ] Other
3.[ ] Caucasian

4. Marital status: 1.[ ] Married

2.[ ] Single and living with partner

5. If you are married or are living with your partner, how long have you shared a common residence?

1.[ ] less than 3 yrs

2.[ ] 3-6 yrs

3.[ ] $7-10 \mathrm{yrs}$

4.[ ] 11-14 yrs

5.[ ] 15 yrs and above

6.[ ] Do not live with spouse.

6. How would you best classify your present job? (Select one)

1.[ ] Administrative 5.[ ] Professional

2.[ ] Blue-collar 6.[ ] Technical

3.[ ] Clerical 7.[ ] Do not work

4.[ ] Managerial 8.[ ] Other

7. How much flexibility do you have in your work schedule to handle family/personal responsibilities?

1.[ ] A lot of flexibility 5.[ ] NA

2.[ ] Some flexibility

3.[ ] Hardly any flexibility

4.[ ] No flexibility at all
8. Based on the work schedules described in the cover letter, which one of the following best describes your present work schedule:

1.[ ] Standard full-time (e.g. 8-5)

2.[ ] Part-time 5.[ ] Compressed

3.[ ] Flexible hours 6.[ ] Other

4.[ ] Job Sharing 7.[ ] NA

9. Please indicate the relative priority of your career and your partner's career.

1.[ ] My career has a much higher priority than my partner's career.

2.[ ] My career has somewhat of a higher priority than my partner's career.

3.[ ] My career has the same priority as my partner's career.

4.[ ] My partner's career has somewhat of a higher priority than my career.

5.[ ] My partner's career has a much higher priority than my career.

6.[ ] NA

If employed, please fill-in the appropriate response for the following questions.

10. Number of regular hours I am HIRED to work per week:

11. Number of regular hours I ACTUALLY work per week:

12. Number of regular hours I would prefer to work per week:

13. Average number of overtime hours worked per week: 
14. How long have you worked in your present job?

Years, months

15. In the past four weeks:

(Enter 0 if none)

a. How may times have you been late to work?

b. While at work, how many times have you been interrupted (e.g. telephone calls) to deal with family/personal-related issues?

c. How many days have you missed work due to family/personal-related issues?

16. Number of children living at home:

$$
\text { N/A [ ] }
$$

17. Age(s) of children living at home: (years)
18. On the average, about how much time do you spend on child-care activities daily?

$$
\text { N/A [ ] hours }
$$

19. Number of elderly relatives living at home:

\section{NA [ ]}

20. On the average, about how much time do you spend on elderly-care activities daily?

$$
\text { NA [ ] hours }
$$

21. On the average, about how much time do you spend on family/ personal activities daily?

hours

22. On the average, about how much time do you spend on work activities daily?

hours

II. Work and Family Role Involvement

If employed, please circle the number of the answer that best represents your response with respect to your immediate household. If the question is Not Applicable, mark X in the NA [ ]. Please respond to the following questions ranging from $1=$ strongly agree to $5=$ strongly disagree.

23. My main satisfaction in life comes $\begin{array}{llrl}\text { strongly } & & \text { strongly } \\ \text { agree } & \text { agree } & \text { neutral disagree } & \text { disagree }\end{array}$ from my work.

24. The most important things that happen to me involve my work.

25. My main satisfaction in life comes from my family/personal life.

26. The most important things that happen to me involve my family/personal life.

27. I frequently think about my family/personal life when I am busy doing something else.

$\begin{array}{lllll}1 & 2 & 3 & 4 & 5\end{array}$


28. I frequently think about my work

$\begin{array}{ccccc}\begin{array}{c}\text { strongly } \\ \text { agree }\end{array} & \text { agree } & \text { neutral } & \begin{array}{r}\text { strongly } \\ \text { disagree } \\ \text { disagree }\end{array} \\ 1 & 2 & 3 & 4 & 5 \\ 1 & 2 & 3 & 4 & 5 \\ 1 & 2 & 3 & 4 & 5\end{array}$

III. Work-Family Conflict

31. My work takes up time that I would like to spend on my family/personal life.

32. My work schedule often conflicts with my family/personal life.

33. My family dislikes how often I am preoccupied with my work while I am at home. $\mathrm{NA}$ [ ]

34. After work, I come home too tired to do some of the things I would like to do.

35. On the job I have so much work to do that it takes away from my personal interests.

36. Because my work is demanding, at times I am irritable at home.

37. The demands of my job make it more difficult to be relaxed at home.

38. My job makes it difficult to be the kind of partner/spouse or parent I would like to be.

$\begin{array}{lllll}1 & 2 & 3 & 4 & 5\end{array}$

My family/personal life takes up time that I would like to spend doing my work.

40. My family life often conflicts with my work schedule.

41. My co-workers dislike how often I am preoccupied with my family/ personal life while I am at work.

42. When I go to work, I am too tired to do some of the things I would like to do.

$\begin{array}{lllll}1 & 2 & 3 & 4 & 5\end{array}$

43. At home, I have so many responsibilities that it takes away from my personal interests.

$\begin{array}{lllll}1 & 2 & 3 & 4 & 5\end{array}$


strongly

agree times I am irritable at work.

45. The demands of my family/personal life make it more difficult to be relaxed while at work.

46. My family/personal life makes it difficult to be the kind of worker I would like to be.

47. Do you have any additional comments? Please attach a separate sheet if necessary.

Thank you for completing the survey.

Please return the survey in the enclosed envelope.

$\begin{array}{lllll}1 & 2 & 3 & 4 & 5\end{array}$

$\begin{array}{lllll}1 & 2 & 3 & 4 & 5\end{array}$

